\title{
Icarus
}

\section{Short lifespans of serpentinization in the rocky core of Enceladus: implications for hydrogen production --Manuscript Draft--}

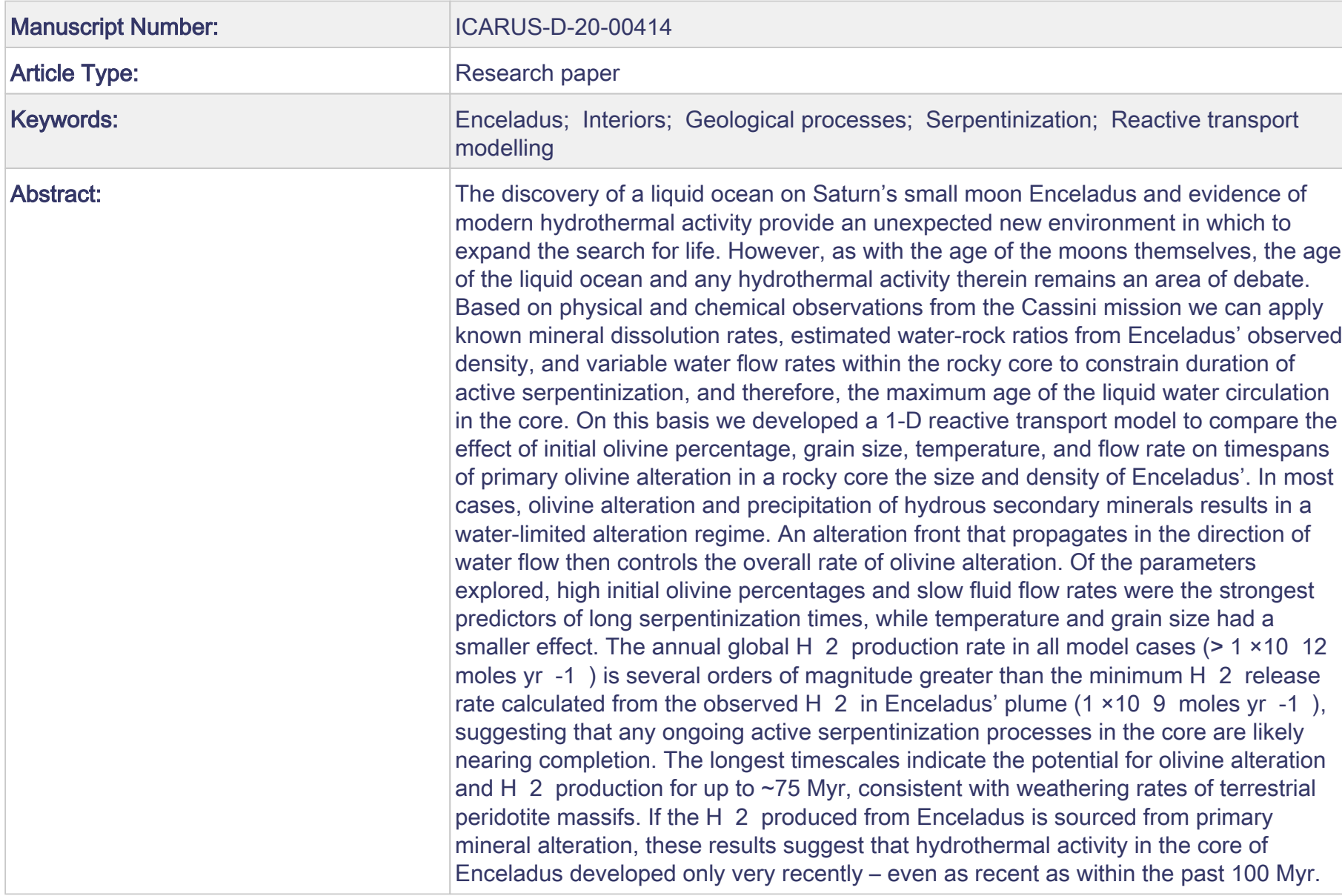




\title{
Short lifespans of serpentinization in the rocky core of Enceladus: implications for hydrogen production
}

\author{
Elsevier $^{1}$ \\ Radarweg 29, Amsterdam \\ 5 \\ A. Zandanel ${ }^{a *}$, L. Truche $^{a}$, R. Hellmann ${ }^{a}$, Andrey Myagkiy ${ }^{a, \dagger}$, G. Choblet ${ }^{b}$, G. Tobie $^{b}$ \\ a ISTerre, UMR 5275, CNRS, Université Grenoble Alpes, 1381 rue de la Piscine, BP53 \\ 38041 Grenoble, CEDEX 9, France \\ ${ }^{b}$ Laboratoire de Planétologie et Géodynamique, UMR 6112, CNRS, Université de Nantes, 2 \\ chemin de la Houssinière, 44300 Nantes, France \\ ${ }^{+}$Current address : Storengy, 92270 Bois-Colombes, France
}

\section{Abstract}

The discovery of a liquid ocean on Saturn's small moon Enceladus and evidence of modern hydrothermal activity provide an unexpected new environment in which to expand the search for life. However, as with the age of the moons themselves, the age of the liquid ocean and any hydrothermal activity therein remains an area of debate. Based on physical and chemical observations from the Cassini mission we can apply known mineral dissolution rates, estimated water-rock ratios from Enceladus' observed density, and variable water flow rates within the rocky core to constrain duration of active serpentinization, and therefore, the maximum age of the liquid water circulation in the core. On this basis we developed a 1-D reactive transport model to compare the effect of initial olivine percentage, grain size, temperature, and flow rate on timespans of primary olivine alteration in a rocky core the size and density of Enceladus'. In most cases, olivine alteration and precipitation of hydrous secondary minerals results in a water-limited alteration regime. An alteration front that propagates in the direction of water flow then controls the overall rate of olivine alteration. Of the parameters explored, high initial olivine percentages and slow fluid flow rates were the strongest predictors of long serpentinization times, while temperature and grain size had a smaller 
effect. The annual global $\mathrm{H}_{2}$ production rate in all model cases $\left(>1 \times 10^{12}\right.$ moles $\left.^{\mathrm{yr}^{-1}}\right)$ is several orders of magnitude greater than the minimum $\mathrm{H}_{2}$ release rate calculated from the observed $\mathrm{H}_{2}$ in Enceladus' plume $\left(1 \times 10^{9}\right.$ moles $\left.\mathrm{yr}^{-1}\right)$, suggesting that any ongoing active serpentinization processes in the core are likely nearing completion. The longest timescales indicate the potential for olivine alteration and $\mathrm{H}_{2}$ production for up to $\sim 75$ Myr, consistent with weathering rates of terrestrial peridotite massifs. If the $\mathrm{H}_{2}$ produced from Enceladus is sourced from primary mineral alteration, these results suggest that hydrothermal activity in the core of Enceladus developed only very recently - even as recent as within the past $100 \mathrm{Myr}$.

Keywords: Enceladus, Interiors, Geological processes, Serpentinization, Reactive transport modelling

\section{Introduction}

Estimating the origin and evolution of the oceans of Saturn's icy moons is an area of research that has rapidly evolved since the acquisition of new data by the CassiniHuygens mission (1997-2017). Geophysical observations acquired by the Cassini spacecraft indicate the presence of a liquid ocean on Enceladus beneath its icy outer shell (Beuthe et al., 2016; Čadek et al., 2016, 2019; Collins \& Goodman, 2007; Iess et al., 2014; Thomas et al., 2016). Gravity data also indicate that the rocky core of Enceladus has a relatively low density (Beuthe et al., 2016; Čadek et al., 2016; Iess et al., 2014), implying porosity of the order of 20-30\% (Choblet et al., 2017). An internal heat source from endogenic activity, likely tidal dissipation in the porous core (Choblet et al., 2017; Liao et al., 2020), is thought to be responsible for anomalously high temperatures and ice shell fracturing at the south pole (Porco et al., 2006; Spencer et al., 2006) collocated with vapor plumes emitting to space (Hansen et al., 2006; Waite et al., 2006). In-situ analyses using Cassini's ion and neutral mass spectrometer (INMS) during close flybys have shown that the vapor plume largely comprises water carrying a number of trace constituents, including organic species and ammonia (Waite et al., 2009, 2017). Salt residues found with water ice in the E-ring of Saturn are thought to be sourced by Enceladus' plumes, further indicating that a liquid ocean currently or 
recently existed and interacted with a rocky core (Postberg et al., 2009, 2011). Moreover, the Cassini Cosmic Dust Analyzer (CDA) revealed the presence of nanometer-sized silica particles originating from the E-ring, indicative of active silicate-water interactions inside Enceladus (Hsu et al., 2015; Sekine et al., 2015). Finally, $\mathrm{H}_{2}$ with relatively high $\mathrm{H}_{2}: \mathrm{CH}_{4}$ ratios was also measured within the vapor plume, both of which are compatible with inorganic $\mathrm{H}_{2}$ production during hydration and alteration of ultramafic rocks (Waite et al., 2017).

A long-standing debate concerns the age and duration of Enceladus' endogenic activity: is it a transient phenomenon, or is it long-lived? The duration of activity is mostly determined by the availability of internal heat sources, which is intimately linked to the moon's orbital evolution through tidal friction (e.g. Lainey et al., 2012; Meyer \& Wisdom, 2007; Neveu \& Rhoden, 2019; K. Zhang \& Nimmo, 2009). Early estimates based on approximate dissipation inside Saturn, which controls the rate of orbital expansion, indicated that, at equilibrium, tidal heating could not exceed $1 \mathrm{GW}$ (Meyer \& Wisdom, 2007), which represents a power at least 5 times smaller than the total power currently emitted at the South Pole (Spencer et al., 2006). This estimate suggested that the activity on Enceladus may be episodic and relatively short-lived (Běhounková et al., 2012; O’Neill \& Nimmo, 2010). Astrometric data then revealed a faster outward migration for Saturn's moons than initially assumed, indicating subsequently that the dissipation inside Saturn is at least 10 times larger than anticipated. This new estimate of Saturn's dissipation implies that 10-15 GW may be generated inside Enceladus at equilibrium (Lainey et al., 2012, 2017). Even if these new constraints solved the power problem, they have raised new issues regarding the origin and age of the moons. More dissipation in Saturn indeed implies rapid orbital expansion and thus suggests that all inner moons were closer to Saturn and its rings in a relatively recent past (Baillié et al., 2019; Charnoz et al., 2011; Neveu \& Rhoden, 2019; Noyelles et al., 2019). The successive formation of Saturn's mid-sized moons (Rhea, Dione, Tethys, Enceladus, and Mimas) from the spreading of initially more massive rings is in line with this constraint (Charnoz et al., 2011; Crida \& Charnoz, 2012). The age of Enceladus and neighboring moons is then strongly linked to the age of the rings.

The latest measurements performed by the Cassini spacecraft during the Grand Finale sequence, including mass determination (Iess et al., 2014) and contamination of 
the rings by non-ice materials (Z. Zhang et al., 2017), were interpreted to mean that the rings are relatively young. This appears consistent with the analysis of Ćuk et al. (2016), who proposed a disruption and re-accretion of the inner moons about 100 My ago in order to explain the orbital configurations of Saturn's moons. The interpretation of a young age of the rings and late formation of the inner moons are, however, questioned by Crida et al. (2019), who argued that the Cassini data is equally compatible with an old ring system. The fresh ice particle supply provided by Enceladus' activity might even dilute the ring pollution and thus apparently rejuvenate old rings.

The debate still remains open: recent observations of Titan's expansion rate (Lainey et al., 2020) finally favor a specific dissipation scenario for the Saturn system termed resonance locking (Fuller et al., 2016). In this conceptual framework, while Saturn's mid-sized inner moons form successively, their age is essentially unconstrained: Enceladus could be between $500 \mathrm{Myr}$ and 4 Gyr old. Even if the ring and inner moons are old, does it also imply that the activity of Enceladus is old and long-lived? Particle deposit features identified on small irregular moons orbiting in the E-ring suggest that the particle accumulation resulting from particle spread in space by Enceladus did not last more than several tens of million years (Hirata et al., 2014), indicating either very short periods of activity during Enceladus's history or a relatively recent onset of cryovolcanic activity. If the surface activity is a direct consequence of internal activity, this might suggest a late initiation of hydrothermal activity.

These geophysical constraints, combined with chemical constraints inferred from Cassini's CDA and INMS data, suggest a novel method of evaluating Enceladus' endogenic activity by estimating the timespan of $\mathrm{H}_{2}$ generation that can result from hydrothermal water-rock reactions within the core. Hydrothermal alteration of ultramafic rocks containing $\mathrm{Fe}^{2+}$-bearing minerals that leads to significant $\mathrm{H}_{2}$ production is a geologically rapid reaction process. The suite of reactions producing $\mathrm{H}_{2}$ as a by-product of hydration of mafic and ultramafic minerals are often termed serpentinization, originally referring to reaction of $\mathrm{Mg}$ - and Fe-bearing olivine (i.e. forsterite and fayalite) to produce serpentine, brucite and magnetite:

$2 \mathrm{Mg}_{2} \mathrm{SiO}_{4}+3 \mathrm{H}_{2} \mathrm{O} \rightarrow \mathrm{Mg}_{3} \mathrm{Si}_{2} \mathrm{O}_{5}(\mathrm{OH})_{4}$ (serpentine) $+\mathrm{Mg}(\mathrm{OH})_{2}$ (brucite) Equation (1)

$$
3 \mathrm{Fe}_{2} \mathrm{SiO}_{4}+2 \mathrm{H}_{2} \mathrm{O} \rightarrow 2 \mathrm{Fe}_{3} \mathrm{O}_{4} \text { (magnetite) }+3 \mathrm{SiO}_{2}+2 \mathrm{H}_{2} \quad \text { Equation (2) }
$$



that with a pristine rocky core of ultramafic mineralogy, oxidation of all Fe-bearing minerals would result in up to $2 \times 10^{20}$ moles $\mathrm{H}_{2}$ produced (Waite et al., 2017). The annual minimum release rate of $\mathrm{H}_{2}$ calculated from its concentration in the vapor plumes is estimated at $1-5 \times 10^{9}$ moles $\mathrm{yr}^{-1}$ (Waite et al., 2017). At this rate, water-rock reactions with only $1 \%$ of the mass of the rocky core could produce the observed amount of $\mathrm{H}_{2}$ for hundreds of millions of years (Waite et al., 2017). However, efficient water-rock interaction processes may result in much faster rates of serpentinization (Malamud \& Prialnik, 2013), and thus a shorter lifetime of active $\mathrm{H}_{2}$ production (Vance $\&$ Melwani Daswani, 2020).

Analogous Earth environments where submarine peridotite (ultramafic rock composed of olivine and pyroxene minerals) weathering takes place offer a range of time intervals for active serpentinization and complete alteration of primary minerals. In the alkaline and low-temperature Lost City hydrothermal field (LCHF, located along the Mid-Atlantic Ridge), the rate of serpentinization is estimated to be between a maximum rate of $5.1 \times 10^{-3} \mathrm{~km}^{3}$ year ${ }^{-1}$ and a conservative rate of $1.2 \times 10^{-4} \mathrm{~km}^{3}$ year (Früh-Green et al., 2003). Based on these rates, total serpentinization of a peridotite core the size of that of Enceladus (Table 1) would take between 56 and $240 \mathrm{Myr}$. In contrast, experimental dissolution studies of olivine powders (Oelkers, 2001; Pokrovsky \& Schott, 2000b)f as well as peridotite rock cores (Malvoisin \& Brunet, 2014) have yielded chemical alteration rates that are orders of magnitude faster than the maximum alteration rates estimated for the serpentinization of peridotite massifs in submarine environments. This discrepancy between field and lab serpentinization rates is often reconciled by invoking greater water-rock ratios in lab experiments compared to submarine peridotite massifs (White \& Brantley, 2003), which emphasizes the importance of rock porosity and water-rock ratios on weathering rates.

While terrestrial peridotite weathering rates present a convenient point of comparison, the physical properties of Enceladus' core differ in important ways from Earth's lithosphere. Specifically, the significantly greater geothermal and geobaric gradients on Earth preclude the widespread existence of cool, low-pressure, highporosity mafic rock on multi-kilometer scales. In contrast to the average geothermal gradient of $25-30{ }^{\circ} \mathrm{C} \mathrm{km}^{-1}$ in Earth (Arndt, 2011), Enceladus' core is estimated to have 
a temperature gradient of less than $1^{\circ} \mathrm{C} \mathrm{km}^{-1}$ (Choblet et al., 2017). From the measured density of Enceladus, the entire $360-400 \mathrm{~km}$ diameter core is thought to be unconsolidated, comparable in porosity and water content to a water-saturated sand or sandstone (20-30\% water-filled porosity, Choblet et al. 2017). Continuous fluid circulation, which is imposed by tidal forcing, coupled with the high porosity of the core suggests that chemical alteration rates may be closer to those determined in laboratory experiments, and thus far faster than those estimated for terrestrial submarine weathering of peridotite. Literature-based alteration rates for a primary $\mathrm{H}_{2}$ producing minerals, variable water flow rates as imposed by heterogenous tidal heating patterns, and water-rock ratios expected from core density models may then be used to estimate timescales of active hydrogen production from primary mineral alteration occurring throughout the rocky core of Enceladus. These timescales can, in turn, be used to place age constraints on the endogenic activity of Enceladus.

Table 1 Estimated physical properties of Enceladus' core

\begin{tabular}{cc}
\hline Property & Value \\
\hline Core porosity & $20 \%$ a \\
Core volume $\left(\mathrm{m}^{3}\right)$ & $2.87 \times 10^{16 \mathrm{~b}}$ \\
Rock mass in core $(\mathrm{kg})$ & $6.26 \times 10^{19 \mathrm{~b}}$ \\
\hline Initial olivine in rock mass & $\mathrm{Sum} \mathrm{H}_{2}$ producible \\
\hline $100 \%:$ & $2.5 \times 10^{20}$ \\
$60 \%:$ & $1.5 \times 10^{20}$ \\
$20 \%:$ & $0.5 \times 10^{20}$
\end{tabular}

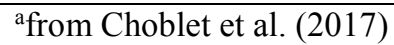

${ }^{\mathrm{b}}$ from Waite et al. (2017)

In order to provide constraints on the timescale of aqueous alteration processes inside Enceladus' core and hence new age estimates on its activity, we present here a 1-D reactive transport model of olivine alteration within an unconsolidated rocky core consistent with that of Enceladus and other mid-sized icy satellites that may have supported liquid water oceans during their evolution. First, we present the 1-D model 
structure and the parameter space of both representative and end-member alteration conditions, assuming tidally driven porous convection of interstitial water (Choblet et al., 2017). Second, we present the results showing alteration times are controlled by the flow rates of water induced by tidal forcing. Third, we define a range of timespans of active olivine dissolution and $\mathrm{H}_{2}$ production from our model, and finally compare these results to conditions within the core of Enceladus and other icy moons.

\section{1-D modelling method}

\subsection{Hydrodynamics and computational parameters}

Olivine dissolution is simulated using a reactive multicomponent 1-D transport model in PHREEQC (V. 3.5.0) (Parkhurst \& Appelo, 2013). The model simulates directional alteration of a vertical column of primary minerals (olivine) by a steady influx of water (input solution) from an overlying liquid ocean. Solute concentrations in every cell are solved by an Advection-Reaction-Dispersion equation in PHREEQC that is described in detail by Myagkiy et al. (2017). With this method, concentrations change by advection along concentration gradients or by reaction with solid material. Dispersion in our model is set to zero. Excluding dispersion will result in a sharper reaction front and higher solute concentration peaks; this model then underestimates spreading of the concentration front and slightly overestimates local solute concentrations.

The entire column initially contains a rock phase made up of a primary mineral in contact with an input solution. The chemistry of the input solution is a dilute $\mathrm{Na}-\mathrm{Cl}$ constituents $\left(\mathrm{mmol} \mathrm{L}^{-1}\right)$ : $[\mathrm{Na}]=122,[\mathrm{Cl}]=78.6,\left[\mathrm{HCO}_{3}\right]=39,\left[\mathrm{NH}_{3}\right]=469,[\mathrm{~K}]=0.6$, $[\mathrm{Si}]=0.011,[\mathrm{Mg}]=0.007,[\mathrm{Al}]=6 \times 10^{-8}$, and $\left.[\mathrm{Fe}]=6 \times 10^{-8}\right)$. This is consistent with a range of ocean compositions predicted by previous models equilibrating a carbonaceous chondrite with water (Zolotov, 2007) as well as with a predicted ocean composition based on analyses of the ice grains from Enceladus' vapor plume (Glein et 
al., 2015; Hsu et al., 2015). The rock phase adopted in our models is composed solely of pristine $\mathrm{Mg}$-richolivine $\left(\mathrm{Mg}_{1.82} \mathrm{Fe}_{0.17} \mathrm{Al}_{0.007} \mathrm{SiO}_{4}\right)$. This composition is consistent with measurements of San Carlos olivine and of olivine compositions in chondrites (Buseck \& Goldstein, 1969; Komatsu et al., 2001; Oelkers et al., 2018). Aluminum is a known trace constituent of olivine and is therefore included in the olivine composition. Olivine is the sole initial mineral in our calculation of $\mathrm{H}_{2}$ production times and benefits from extensive dissolution kinetics data. While olivine is one of the primary constituents of chondrites, it is far from the sole mineral thought to make up Enceladus' core. Pyroxenes, native iron, and iron-nickel alloys are all found in chondrites and all contribute to $\mathrm{H}_{2}$ generation during water-rock interaction (Holm et al., 2015). Olivine dissolution rates are here considered as a proxy for other $\mathrm{Mg}$-Fe silicates, as pyroxene minerals have similar dissolution rates compared to olivine in the high $\mathrm{pH}$ range (Bandstra et al., 2008). Native iron and iron-nickel alloys are not included in our initial mineral assemblage because oxidation of native metals and alloys, and therefore $\mathrm{H}_{2}$ kinetic production rates, is instantaneous compared to dissolution rates of silicates. Inclusion of native metals and alloys in the initial model would then increase the initial amount of $\mathrm{H}_{2}$ produced but would not be expected to increase the overall duration of $\mathrm{H}_{2}$ production. In addition, the inclusion of additional primary silicate phases (e.g. quartz, amorphous silica) in the initial rock assemblages may contribute to the silica budget and control secondary mineral formation during alteration (Frost \& Beard, 2007). Sensitivity tests that included amorphous silica and quartz in the initial rock assemblage of our models showed that including these minerals had little effect on the secondary mineral paragenesis in the conditions of our model, and no effect on the duration of active $\mathrm{H}_{2}$ production.

All of our models simulate the geochemical evolution of a $140 \mathrm{~km}$ long 1-D column, composed of 3500 cells of $40 \mathrm{~m}$ length (Fig. 1). $140 \mathrm{~km}$ represents $\sim 80 \%$ of the core radius as estimated by geophysical observations of Enceladus (Čadek et al., 2016, 2019; Iess et al., 2014; McKinnon, 2015); an analysis of the impact of the column length on the results is included in the discussion section. Porosity for the 1-D column is set at $20 \%$, consistent with the expected porosity given the density of Enceladus (Choblet et al., 2017) and the compaction regime of a small satellite (Vance et al., 2007). Due to code limitations, porosity remains constant in the column for the model duration. It 
should be noted that while the available porosity remains constant, the amount of waterfilled porosity within the pores is allowed to vary (decrease) due to hydration reactions during transport and therefore the water-rock ratio necessarily varies as well. In real weathering profiles, changes in the volume and density of the rock phase during precipitation of secondary minerals can result in complex processes such as compaction or fracturing (Farough et al., 2016; Lafay et al., 2018; L. Zhang et al., 2019) that are not modelled here.
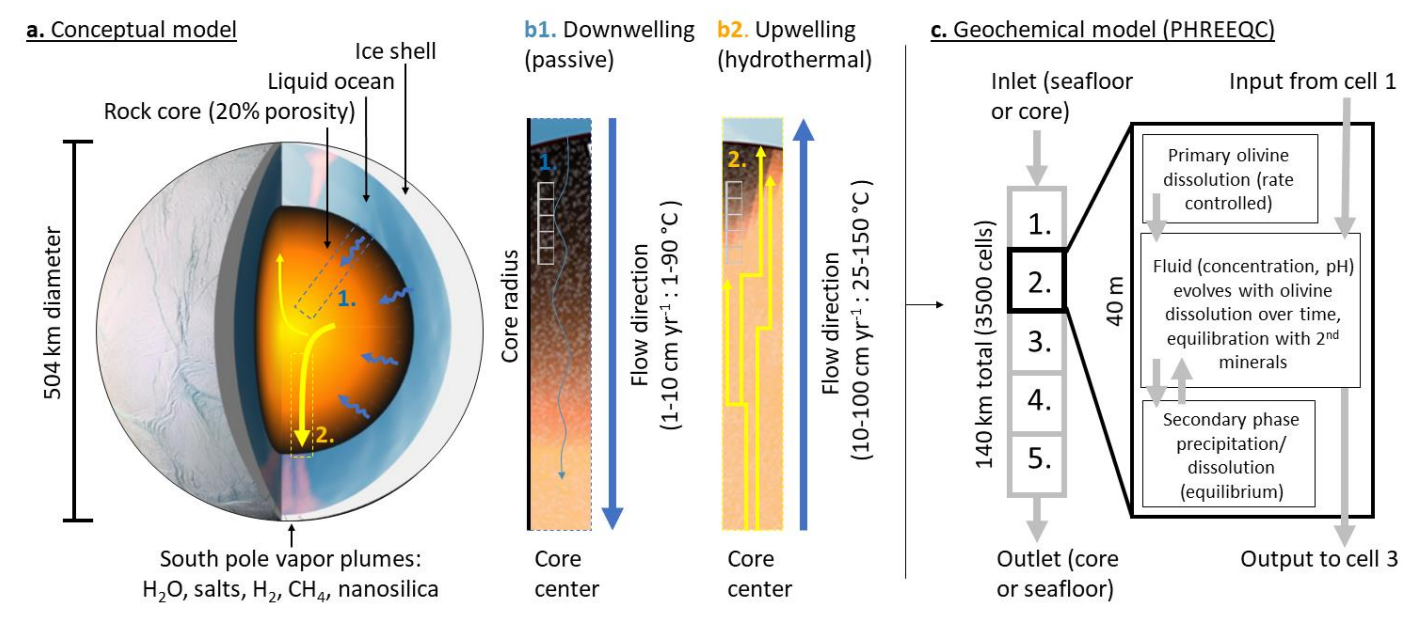

Fig. 1 a. Conceptual model of flow-driven chemical alteration reactions in Enceladus' core (illustration adapted from Choblet et al. 2017): b1) "downwelling" alteration and b2) “upwelling” alteration. c. The PHREEQC geochemical model.

A flux boundary condition is imposed on the first cell of the column as fluid input, and on the last cell as fluid output. The flow rate is imposed by selecting the residence time that each batch of fluid interacts with the rock phase (primary olivine + secondary paragenesis) in a single $40 \mathrm{~m}$ cell before the fluid is shifted to the next cell in the column (Fig. 1). Each specific flow rate, equal to the residence time divided by the length of the cell $(40 \mathrm{~m})$, remains constant during each run (Table 2). The total computing time for 1-D transport calculations is the number of times the solution is shifted vertically through the column. The geologic time represented by each run is determined by multiplying the residence time of the solution in a single cell by the number of times 
the solution is shifted. Each model runs for an equivalent geologic time of at least 1 Myr, or until all the primary mineral (olivine) in the core is exhausted and the secondary paragenesis is at equilibrium with the incoming fluid.

Table 2 Model cases

\begin{tabular}{|c|c|c|c|c|c|c|c|c|}
\hline Case & $\begin{array}{c}\mathbf{T} \\
\left({ }^{\circ} \mathbf{C}\right)\end{array}$ & $\begin{array}{c}V \\
\left(\mathrm{~cm} \mathrm{yr} \mathbf{r}^{-1}\right)\end{array}$ & $\begin{array}{c}\text { pH } \\
(\text { at T) }\end{array}$ & $\begin{array}{c}\text { grain sz } \\
(\mathbf{m m})\end{array}$ & O:W & $t_{\mathrm{d}}$ & $\begin{array}{c}R_{\text {front }} \\
\mathbf{k m ~ M y r}^{-1}\end{array}$ & Flow \\
\hline 1 & 1 & 1 & 11 & 0.1 & $4.0: 1$ & $35 \mathrm{Myr}$ & 3.95 & down \\
\hline 2 & 1 & 1 & 11 & 0.1 & $2.5: 1$ & $22 \mathrm{Myr}$ & 6.34 & down \\
\hline 3 & 1 & 1 & 11 & 0.1 & $1.0: 1$ & $300,000 \mathrm{yr}$ & N/A & down \\
\hline 4 & 1 & 1 & 11 & 1 & 4.0:1 & $37 \mathrm{Myr}$ & 3.89 & down \\
\hline 5 & 1 & 1 & 11 & 5 & $4.0: 1$ & $58 \mathrm{Myr}$ & $3.80^{*}$ & down \\
\hline 6 & 25 & 1 & 10.7 & 0.1 & $4.0: 1$ & $35 \mathrm{Myr}$ & 4.02 & down \\
\hline 7 & 90 & 1 & 10.3 & 0.1 & $4.0: 1$ & $35 \mathrm{Myr}$ & 4.03 & up \\
\hline 8 & 150 & 1 & 9.9 & 0.1 & $4.0: 1$ & $35 \mathrm{Myr}$ & 4.03 & up \\
\hline 9 & 150 & 10 & 9.9 & 0.1 & $4.0: 1$ & $4 \mathrm{Myr}$ & 40 & up \\
\hline 10 & 150 & 100 & 9.9 & 0.1 & $4.0: 1$ & $380,000 \mathrm{yr}$ & 432 & up \\
\hline
\end{tabular}

Temperature ( $T$ ) and flow rate $(V)$ are constant for each case. $\mathrm{pH}$ is of the input solution, "grain sz" indicates the radius of the initial olivine grains. $\mathrm{O}: \mathrm{W}$ is an olivine:water volume ratio. "Flow" describes whether the $V$ and $T$ are consistent with upwelling fluid or downwelling. $t_{\mathrm{d}}=$ time until all olivine in the column has been completely dissolved, and $R_{\text {front }}=$ propagation rate of the alteration front (if formed) in $\mathrm{km} \mathrm{Myr}^{-1}$.

$* \boldsymbol{R}_{\text {front }}$ for case 5 is calculated for the propagation rate after the formation of an alteration front at $\sim 28 \mathrm{Myr}$.

Models use one of three different initial olivine:water $(\mathrm{O}: \mathrm{W})$ volume ratios: high (4:1), medium (2.5:1) and low (0.8:1). While we do not include additional primary minerals, the $\mathrm{O}: \mathrm{W}$ ratios can be equated to a percent of the rock mass of the core. Given an assumed and constant $20 \%$ water-filled porosity, a core of 80 volume $\%$ olivine (equal to 100 volume $\%$ of the rock phase) has a $4: 1$ volume ratio of $\mathrm{O}: \mathrm{W}$. In this manner, the high, medium, and low initial olivine ratios can be correlated to 80,50 , and $17 \%$ of the core volume, respectively (or 100,60 , and $20 \%$ of the rock phase by 
volume). The $\mathrm{O}: \mathrm{W}$ ratios were chosen as representative of the range of olivine percentages found in chondrites (Pollack \& Chi, 1972). Medium and low O:W ratios are representative of chondrites where a portion of the initial olivine has already undergone aqueous alteration to secondary clay and serpentine minerals (Rubin et al., 2007; Velbel et al., 2012). While the current estimates for a low density core are not consistent with a core composed of $80 \%$ unaltered olivine (Choblet et al., 2017; Waite et al., 2017), the high O:W model is nevertheless included here to represent an endmember scenario of maximum initial olivine. As the amount of $\mathrm{H}_{2}$ produced is directly proportional to the amount of initial olivine (Eqs. 1 and 2), decreasing the initial olivine percent results in to-a decrease in the total amount of $\mathrm{H}_{2}$ that can be produced (Table 1). The majority of runs use an olivine grain size with $0.1 \mathrm{~mm}$ radius, consistent with the average size of olivine chondrules in a collection of carbonaceous chondrites (Rubin, 1989). We also ran cases with olivine grain sizes of $1 \mathrm{~mm}$ and $5 \mathrm{~mm}$ that simulate larger or more resistant olivine grains (Browning et al., 1996). Specific details of solution $\mathrm{pH}, \mathrm{O}: \mathrm{W}$ ratio, and other model parameters are shown in Table 2.

We ran a series of model cases at different temperatures and flow rates (Table 2) consistent with temperatures and flow rates constrained for Enceladus' core by Choblet et al. (2017). In the present study we focus on alteration below $150{ }^{\circ} \mathrm{C}$, where olivine alteration is slower, to illustrate the maximum timescales of olivine dissolution and $\mathrm{H}_{2}$ production. Computational limitations of the code required that flow rate (water velocity) be held constant over the length of each column for the entire run. Columns were reacted at one of three flow rates: 1,10 , or $100 \mathrm{~cm} \mathrm{yr}^{-1}$, corresponding to the range of flow rates obtained by Choblet et al. (2017) for rock permeabilities between $10^{-12}$ to $10^{-15}$. Temperature was also held constant over time and depth at one of 4 representative values $\left(1,25,90\right.$, or $\left.150{ }^{\circ} \mathrm{C}\right)$. We assume that water flow completes a circuit from seafloor to core center (downwelling) and from core center to seafloor (upwelling), where the paired temperature and flow rate of each case are relevant either to downwelling (comparatively cold, slow-flow) or upwelling (comparatively hot, fastflow). As the temperatures of the interior of Enceladus are expected to change over time, some ranges of temperatures and flow rates that may occur in downwelling conditions for periods of the core evolution are consistent with upwelling conditions at 
other times. Thus, each 1-D case can represent either a downwelling case or an upwelling case as indicated in Table 2 and illustrated in Fig. 1.

\subsection{Geochemical parameters: rate-controlled olivine dissolution}

Geochemical calculations with PHREEQC used the associated 1lnl.dat thermodynamic database (Johnson et al., 2000), modified for this study to prevent redox equilibrium between two separate redox couples: $\mathrm{NH}_{3}-\mathrm{N}_{2}$ and $\mathrm{CO}_{2}-\mathrm{CH}_{4}$. Redox equilibrium between dissolved $\mathrm{NH}_{3}$ and $\mathrm{N}_{2}$ is kinetically hindered at temperatures at or below $300^{\circ} \mathrm{C}$ (Sekine et al., 2015), and the low $\mathrm{N}_{2}$ measured in Enceladus' plume (Hansen et al., 2011) suggests $\mathrm{NH}_{3}$ oxidation is not significant (Waite et al., 2009). For that reason, the nitrogen-bearing species were decoupled in our database to prevent thermodynamic equilibration of $\mathrm{NH}_{3}$ to $\mathrm{N}_{2}+\mathrm{H}_{2} \mathrm{O}$. Similarly, $\mathrm{H}_{2}$ was decoupled from carbonate species in the database to prevent complete oxidation of $\mathrm{CO}_{2}$ to $\mathrm{CH}_{4}$, which is incompatible with the elevated $\mathrm{H}_{2}: \mathrm{CH}_{4}$ ratio measured in the plume (Waite et al., 2017).

The rate-controlled dissolution of olivine and the precipitation (or re-dissolution) of all secondary phases according to their chemical saturation in the fluid are treated as two separate steps in the 1-D model. Olivine dissolution in our model occurs by the following reaction:

$$
\mathrm{Mg}_{1.82} \mathrm{Fe}_{0.17} \mathrm{Al}_{0.007} \mathrm{SiO}_{4}+4 \mathrm{H}^{+}=1.82 \mathrm{Mg}^{2+}+0.17 \mathrm{Fe}^{2+}+0.007 \mathrm{Al}^{3+}+\mathrm{SiO}_{2}+2 \mathrm{H}_{2} \mathrm{O}
$$

Equation (3)

The dissolution process described in Eq. 3 can be considered an elementary reaction of the complex serpentinization reactions described in Eqs. 1 and 2. Rate data for Eq. 3 are readily available in the literature (Bandstra et al., 2008; Oelkers, 2001; Pokrovsky \& Schott, 2000a; Rimstidt et al., 2012). Even though published kinetic data exist for serpentinization reactions at hydrothermal temperatures (Lamadrid et al., 2017; Malvoisin et al., 2012; McCollom et al., 2016, 2020), we used olivine dissolution rates rather than serpentinization rates because we are not aware of appropriate rate data for serpentinization reactions at the much lower temperatures used in our model. Lacking rate data at low temperatures, precipitation of secondary serpentinite minerals in our 
model (chrysotile, brucite, magnetite) is executed instantaneously as a separate step rather than as part of an integrated serpentinization process. Our model does not incorporate potentially competing alteration behaviors such as directly coupled dissolution-serpentinization reactions (Lafay et al., 2012) or kinetic retardation by secondary phases (Daval et al., 2011; Park \& Fan, 2004). Instead, olivine dissolution functions as the rate-limiting reaction of serpentinization such as proposed by the experimental studies of Malvoisin et al. (2012) and Okamoto et al. (2011).

Aggregated empirical data for San Carlos olivine dissolution suggest that $\mathrm{pH}$ and temperature are responsible for up to $90 \%$ of the variability in empirically-derived dissolution rates (Rimstidt et al., 2012). The other 10\% of variability is influenced by a number of factors, including water activities of $<0.9$. The precipitation of hydrous minerals and the resulting concentration of soluble species in the remaining fluid results in water activities $<0.9$ throughout the column in many of the runs. For this reason, we chose to use a specific dissolution rate law for olivine that includes terms for both $\mathrm{pH}$ and water activity (Olsen et al., 2015):

$$
\log r=[6.05-3683 *(1 / \mathrm{T})]-0.52 \mathrm{pH}+3.26 \log a_{\mathrm{H}_{2} \mathrm{O}}
$$

Equation (4)

where $\log r$ is the dissolution rate of olivine in mol m-2 $\mathrm{s}^{-1}$ at $25{ }^{\circ} \mathrm{C}$, and the temperature dependence (with $\mathrm{T}$ in Kelvin) is calculated as in the general kinetic rate law published in Rimstidt et al. (2012). As PHREEQC requires a non-zero water activity for computation, Eq. 4 also ensures convergence of the numerical method during long alteration timescales where the reactive transport model would otherwise allow the precipitation of hydrous minerals to consume all of the water in the column. No term relating the olivine dissolution rate to the Gibbs free energy of reaction $(\Delta G)$ is included in Eq. 4: as less soluble secondary minerals are allowed to precipitate, the fluid-mineral system is always out of equilibrium (undersaturated) with respect to olivine, and therefore the far-from-equilibrium rate of Eq. 4 can be used. The pH term, as integrated in Eq. 4, assumes a linear decrease in the dissolution rate $r$ with increasing $\mathrm{pH}$; however, it is known that this dependence is less pronounced at $\mathrm{pH}>6$ (McCollom et al., 2020; Wogelius \& Walther, 1992). Because of this, the dissolution rate law used in Eq. 4 then calculates slower rates of olivine dissolution than those calculated using 
dissolution rate laws resolved over the entire $\mathrm{pH}$ range (e.g. Pokrovsky \& Schott, 2000b; Rimstidt et al., 2012).

The specific olivine dissolution rate expressed by Eq. 4 is embedded in a general reaction rate formula given by:

$$
R_{d}=r\left(\frac{\mathrm{A}_{0}}{\mathrm{~V}}\right)\left(\frac{\mathrm{m}}{\mathrm{m}_{0}}\right)^{n}
$$

where $R_{d}$ is the overall reaction rate $\left(\mathrm{mol} \mathrm{L}^{-1} \mathrm{~s}^{-1}\right), r$ is the specific dissolution rate from Eq. $4, \mathrm{~A}_{0}$ is the initial specific surface area of the olivine $\left(\mathrm{m}^{2} \mathrm{~kg}^{-1}\right.$ rock, calculated geometrically from the selected grain size), $\mathrm{V}$ is the volume of solution in contact with the olivine grains ( $\mathrm{L} \mathrm{kg}^{-1}$ rock); the $\mathrm{A}_{0} / \mathrm{V}$ factor approximates the initial olivine surface area to fluid ratio. $\mathrm{m}_{0}$ is initial moles of reactant, and $\mathrm{m}$ is the moles of reactant at the computational time (Appelo \& Postma, 2004). In fact, m represents the moles of unaltered olivine at time step $t$, and $\mathrm{m}_{0}$ is a term that normalizes the moles of olivine at time step $t$ to a theoretical initial number of olivine moles $\left(\mathrm{m}_{0}=100 \mathrm{in}\right.$ all runs $) .\left(\mathrm{m} / \mathrm{m}_{0}\right)$ can be considered an aging term that serves to decreases the general rate $R_{d}$ during dissolution (Appelo \& Postma, 2004; Christoffersen, 1976). $n$ is a factor that scales $\left(\mathrm{m} / \mathrm{m}_{0}\right)$ to simulate the decreases in reactive surface sites (reactive surface area) during aging, where $n=0.67$ (or 2/3) represents a monodisperse grain size population (Dixon $\&$ Hendrix, 1993). As the effect of grain size is explicitly explored as a separate variable in this study, $n=0.67$ was used in all models.

The rate expression given by Eq. 5 is employed by PHREEQC at each timestep to calculate olivine dissolution reaction progress. After each kinetically-controlled reaction step, thermodynamic mineral saturation indices are calculated from the final fluid composition in each cell. Where selected secondary phases reach chemical saturation in solution, these minerals are instantaneously precipitated in an amount proportional to their chemical saturation (or over-saturation). The secondary phases in our model includes those minerals that commonly occur during olivine alteration: chrysotile (serpentine), amorphous silica, Mg-smectite, brucite, gibbsite, magnesite, and magnetite. These phases are allowed to precipitate, or even re-dissolve, based on their thermodynamic stability. Talc was included in the secondary mineral assemblage at $150^{\circ} \mathrm{C}$. We note that although field studies have presented evidence that low- 
temperature serpentine minerals may form at temperatures of $25{ }^{\circ} \mathrm{C}$ or below in peridotites (Okland et al., 2012; Pfeifer, 1977), there is no consensus as to whether a minimum temperature for the formation of serpentine minerals exists. Chrysotile is nevertheless included as a secondary mineral in all models, as the long reaction times support the potential for its formation and sensitivity analyses show that its inclusion does not affect rates of olivine dissolution nor $\mathrm{H}_{2}$ production.

Global rates of $\mathrm{H}_{2}$ production are calculated by normalizing the total moles of $\mathrm{H}_{2}$ produced in each time step in the entire column to the fixed value of the initial moles of olivine in the column, giving a rate of $\mathrm{H}_{2}$ production: mol $_{\mathrm{H} 2}$ mol $_{\text {initial olvine }}{ }^{-1}$ year ${ }^{-1}$. Annual $\mathrm{H}_{2}$ production in the column can then be scaled to annual global production by estimating the quantity of moles of olivine initially present in the rocky core from the imposed $\mathrm{O}: \mathrm{W}$ volume ratios, the molar volume of olivine, and the inferred volume of Enceladus' core (Table 1). Limitations of the code prevent exsolution of $\mathrm{H}_{2}$ from the fluid during transport, but the complete exsolution of all $\mathrm{H}_{2}$ produced would almost certainly not occur instantaneously at the low temperatures in downwelling regions. Moreover, some $\mathrm{H}_{2}$ would remain dissolved in the fluid and percolate out of the core by fluid transport. An additional examination of the role of transport through the core after $\mathrm{H}_{2}$ production is included in the discussion section.

\section{Results and discussion}

\subsection{The 1-D transport model: water-limited alteration}

The amount of olivine in the 1-D column initially decreases while interacting with the initial solution in the porous column (Fig. 2). This initial period of elevated waterrock interaction is analogous to an early phase of water-rock differentiation in small satellites. During this early phase water ice, initially homogeneously integrated with other solid phases, melts and migrates through the rock phase to form a liquid reservoir (ocean) differentiated from the rocky core (Malamud \& Prialnik, 2016; Schubert et al., 2007; Vance et al., 2007). During this initial period in our models, olivine dissolution 
(Eq. 3) stoichiometrically releases $\mathrm{Mg}^{2+}, \mathrm{Fe}^{2+}, \mathrm{Al}^{3+}$, and $\mathrm{SiO}_{2}$ into the fluid at rates dictated by Eq. 5. After this initial period of dissolution, precipitation of secondary minerals causes consumption of the water in each cell (e.g. Eqs. 1 and 2). The decreasing water mass and increasing concentration of solutes in the remaining fluid causes the water activity to decrease from its original value of 1 . As olivine dissolution is progressively retarded by decreasing water activity (Eq. 4), the dissolution rate slows during reactive transport until olivine dissolution becomes negligible (2 Myr or less). Without a mechanism to re-introduce water to the core, water-rock interaction would effectively halt after this period of water migration through (and reaction with) the rock core (see e.g. Malamud \& Prialnik, 2013, 2016). The incorporation of tidally-driven water circulation through the core provides a mechanism for the reintroduction of water from the overlying liquid ocean: in our model, this is imposed through the fluid input and fluid transport in the column (Fig. 1). An alteration front then forms, where olivine dissolution and secondary precipitation occur only where water is reintroduced to the cells from fluid transport. Ongoing fluid input and transport through the column to the alteration front is what drives its progression in the direction of flow. The time duration for the dissolution of all the olivine in the column $\left(t_{d}\right)$ is then dependent on the rate of propagation of the alteration front $\left(R_{\text {front }}\right)$, or stated another way, $t_{d}$ is contingent upon the front passing completely through the column.

The general features of an alteration profile are illustrated in Fig. 2 based on a model run at $25{ }^{\circ} \mathrm{C}\left(\mathrm{O}: \mathrm{W}=4: 1\right.$, grain size $=0.1 \mathrm{~mm}$, flow rate $\left.=1 \mathrm{~cm} \mathrm{yr}^{-1}\right)$. Fig. 2a shows that any given time, $\mathrm{pH}$ in the column increases in the direction of flow as the incoming fluid chemistry is progressively buffered by serpentinization reactions and equilibration with secondary brucite and chrysotile (Leong \& Shock, 2020). Fig. 2 b shows the moles of $\mathrm{H}_{2}$ produced in the column as a function of depth. We identified three zones with distinct mineralogy and reactions: an "altered" sector upstream of active alteration, where olivine is completely dissolved (i.e. depleted) and secondary mineralogy is at equilibrium with the incoming fluid; an "alteration front" of active olivine dissolution and hydrous secondary mineral precipitation; and a "water-limited" sector downstream of the front where little olivine dissolution occurs due to low water activity (Fig. 2). The altered sector is dominated by the secondary paragenesis, predominantly chrysotile with small amounts of brucite, magnesite, and magnetite (Fig. 2c-d). pH remains equal 
to the $\mathrm{pH}$ of the incoming fluid. Within the alteration front, olivine actively dissolves and equilibration of the fluid in each cell at each time step causes $\mathrm{Fe}^{2+}$ oxidation to $\mathrm{Fe}^{3+}$, $\mathrm{H}_{2}$ production, $\mathrm{pH}$ increase, and precipitation of chrysotile, magnesite, and brucite (Fig. $2 \mathrm{a}-\mathrm{c})$. This is apparent from Fig. $2 \mathrm{~b}$, where $\mathrm{H}_{2}$ production occurs only at the depth of the alteration front: at any given time, less olivine dissolves at the upstream trailing edge of the alteration front where olivine mass is decreased from previous fluid introduction; near the center of the alteration front, more olivine remains and more $\mathrm{H}_{2}$ is produced; then at the downstream leading edge of the alteration front olivine dissolution and $\mathrm{H}_{2}$ production decrease again as the increasing $\mathrm{pH}$ and decreasing water activity retard the olivine dissolution rate (Eq. 4). We define the leading edge of the alteration front as where olivine dissolution and $\mathrm{H}_{2}$ production in the downstream edge of the front are near-zero, and the trailing edge as the first cell in the direction of flow to contain a non-zero amount of remaining olivine. In the water-limited sector downstream of the alteration front, olivine remains the principal mineral component with some percent of secondary minerals that precipitated during the initial period of water-rock interaction. The $\mathrm{pH}$ in the water-limited zone is higher than that of the incoming seawater (Fig. 2a), having been buffered by the alteration process upstream.
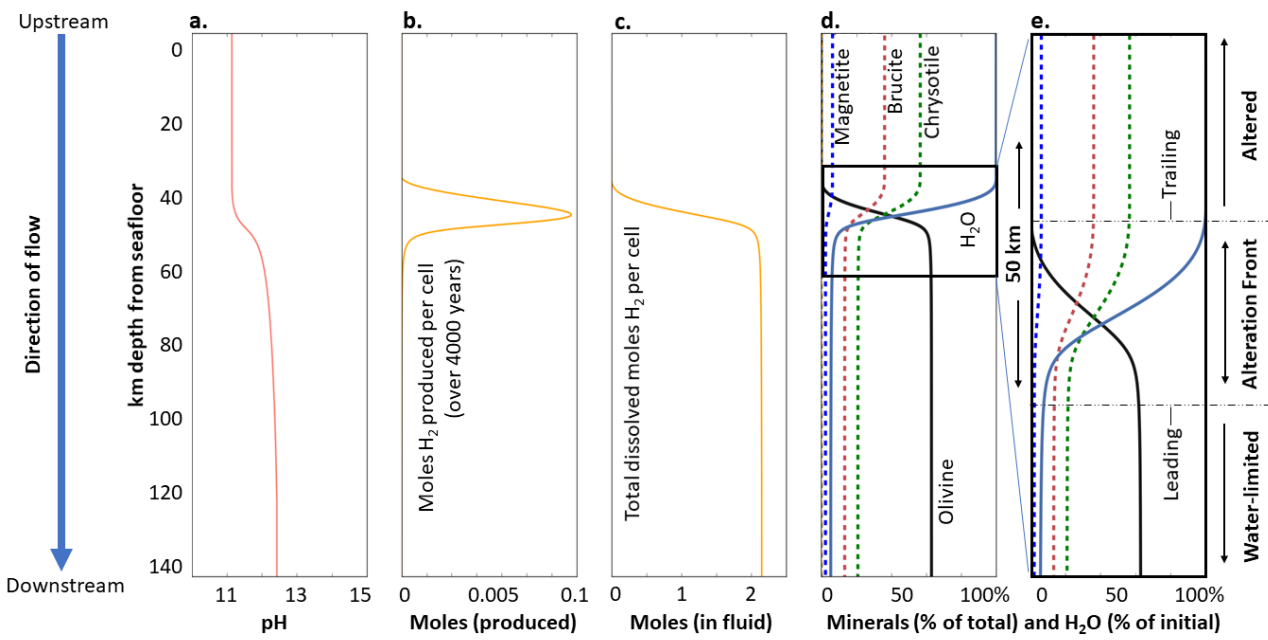

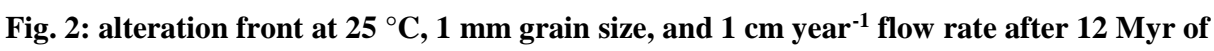
reaction. a. $\mathbf{p H}$ of the fluid in each cell. b. $\mathrm{H}_{2}$ production in total moles produced per cell in one time step. c. total moles of dissolved $\mathrm{H}_{2}$ in the fluid phase in each cell: d. Mineralogy 
regimes in the column: "Minerals (\% of total)" is calculated as a percent of the total moles of all minerals in a given cell, and " $\mathrm{H}_{2} \mathrm{O}$ (\% of initial)" represents what how much of the 20 $\%$ porosity is water-filled. e. Features of the alteration front. The leading and trailing edges of the alteration front are annotated.

The effect of the various parameters we explored in our models on the shape and the propagation rate of the alteration front through the core is shown in Fig. 3. Increasing the fluid flow rate has no effect on the shape of the alteration front but causes $R_{\text {front }}$ to increase (Fig. 3a). In Fig. 3b it can be seen that the alteration front changes from a very sharp step function-like profile with a $5 \mathrm{~km}$ width $(0.1 \mathrm{~mm}$ grain size $)$ to a broad sigmoidal front with a width of $70 \mathrm{~km}$ ( $5 \mathrm{~mm}$ grain size). Grain size also affects the timing and depth of formation of the alteration front: larger grain sizes delay the formation of an alteration front as the proportionately smaller specific surface area slows local olivine dissolution rates, allowing water to continue flowing through the entire column without being completely consumed (Eq. 2). Once the alteration front is formed, however, changes to grain size have a relatively minor effect on $R_{\text {front }}$ (Table 2). The initial O:W ratio (Fig. 3c) affects both the formation of an alteration front and the total olivine dissolution times $\left(t_{\mathrm{d}}\right)$. Taking the case with low initial olivine content (case 3, O:W $=0.8: 1$, grain size $=0.1 \mathrm{~mm}, \mathrm{~T}=1{ }^{\circ} \mathrm{C}$, flow rate $=1 \mathrm{~cm} \mathrm{yr}^{-1}$ ), all of the initial olivine in the column is dissolved and converted to secondary minerals during the initial stage of water-rock interaction. In this case $t_{\mathrm{d}}<1 \mathrm{Myr}$, and is not significantly affected by flow rate because an alteration front never forms. The dependency of the relative amounts of olivine remaining after the initial water-rock interaction stage on the initial O:W ratio is shown in Fig. 3c. The final parameter, temperature, alters the overall shape of the alteration front (Fig. $3 \mathrm{~d}$ ). At $1{ }^{\circ} \mathrm{C}$, the sigmoidal front has a shallow gradient, extending over several tens of $\mathrm{km}$, while at $150{ }^{\circ} \mathrm{C}$, the front is sharp and resembles a step function. 


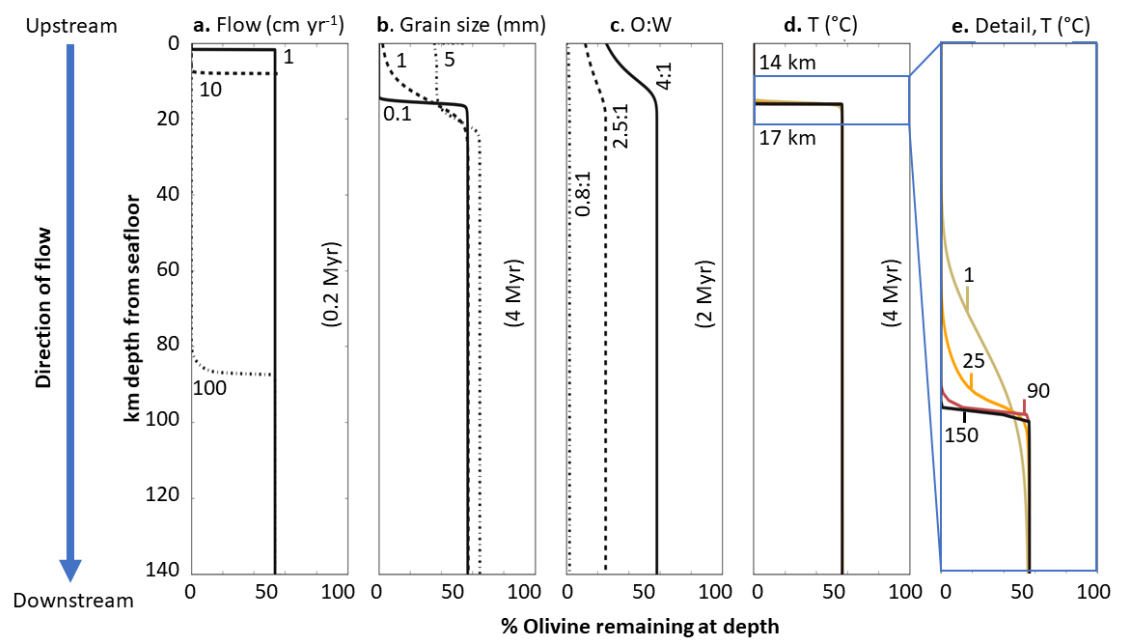

Fig. 3: factors influencing the vertical rate of progress of the alteration front. a. Effect of flow rate $\left(O: W=4: 1\right.$, grain size $\left.=0.1 \mathrm{~mm}, \mathrm{~T}=150{ }^{\circ} \mathrm{C}\right)$. b. Effect of grain size $(\mathrm{O}: \mathrm{W}=4: 1$, flow rate $=1 \mathrm{~cm} y r-1, T=1{ }^{\circ} \mathrm{C}$. c. Effect of the initial $\mathrm{O}: \mathrm{W}$ (grain size $=0.1 \mathrm{~mm}$, flow rate $\left.=1 \mathrm{~cm} \mathrm{yr}-1, \mathrm{~T}=1{ }^{\circ} \mathrm{C}\right) . \mathrm{d}$ and e. Effect of temperature from 1 to $150{ }^{\circ} \mathrm{C}(\mathrm{O}: \mathrm{W}=4.1$, grain size $=0.1 \mathrm{~mm}$, flow rate $\left.=1 \mathrm{~cm} \mathrm{yr}^{-1}\right)$.

Once formed, the propagation of the alteration front through the core controls the time required for total alteration of olivine. The dependence of $R_{\text {front }}$ on temperature and flow rate is graphically shown in Fig. 4. Figure 4a shows the depth of the alteration front over time, where the depth is defined by the trailing edge of the alteration front (Fig 2e). Six different cases are shown (all starting with $\mathrm{O}: \mathrm{W}$ ratio $=4: 1$ and grain size $=0.1 \mathrm{~mm}$ ): three cases at $150{ }^{\circ} \mathrm{C}$ with flow rates of 1,10 , and $100 \mathrm{~cm} \mathrm{yr}^{-1}$ to simulate upwelling (Fig 4a); and three additional cases with a $1 \mathrm{~cm} \mathrm{yr}^{-1}$ flow rate at temperatures of 1,25 , and $90^{\circ} \mathrm{C}$ to simulate downwelling (Fig. 4b). By comparing Figs. 4a and 4b it is apparent that the $R_{\text {front }}$ is much more sensitive to flow rate than temperature. By regressing $R_{\text {front }}\left(\mathrm{km} \mathrm{Myr}^{-1}\right)$ as a function of flow rate and temperature, the sensitivity of the propagation rate with respect to these two parameters can be quantified (Figs. 4c, d). Figure $4 \mathrm{c}$ illustrates that $R_{\text {front }}$ scales linearly with flow rate over the range of flow rates explored here. The effect of fluid flow rate on $R_{\text {front }}$ (and therefore $t_{\mathrm{d}}$ ) is pronounced: increasing the flow rate from $1 \mathrm{~cm} \mathrm{yr}^{-1}$ to $10 \mathrm{~cm} \mathrm{yr}^{-1}$ decreases $t_{\mathrm{d}}$ from 35 
Myr to 4 Myr, which represents a relative decrease of more than $80 \%$ (Fig. 4a). The overall effect of temperature on olivine alteration times is comparatively weak (Fig. 4b): increasing the temperature from 1 to $150^{\circ} \mathrm{C}$ decreases $t_{\mathrm{d}}$ by less than $5 \mathrm{Myr}(<15$ $\%$ relative decrease). $R_{\text {front }}$ scales logarithmically with respect to temperature (Fig. $4 \mathrm{~d}$ ).
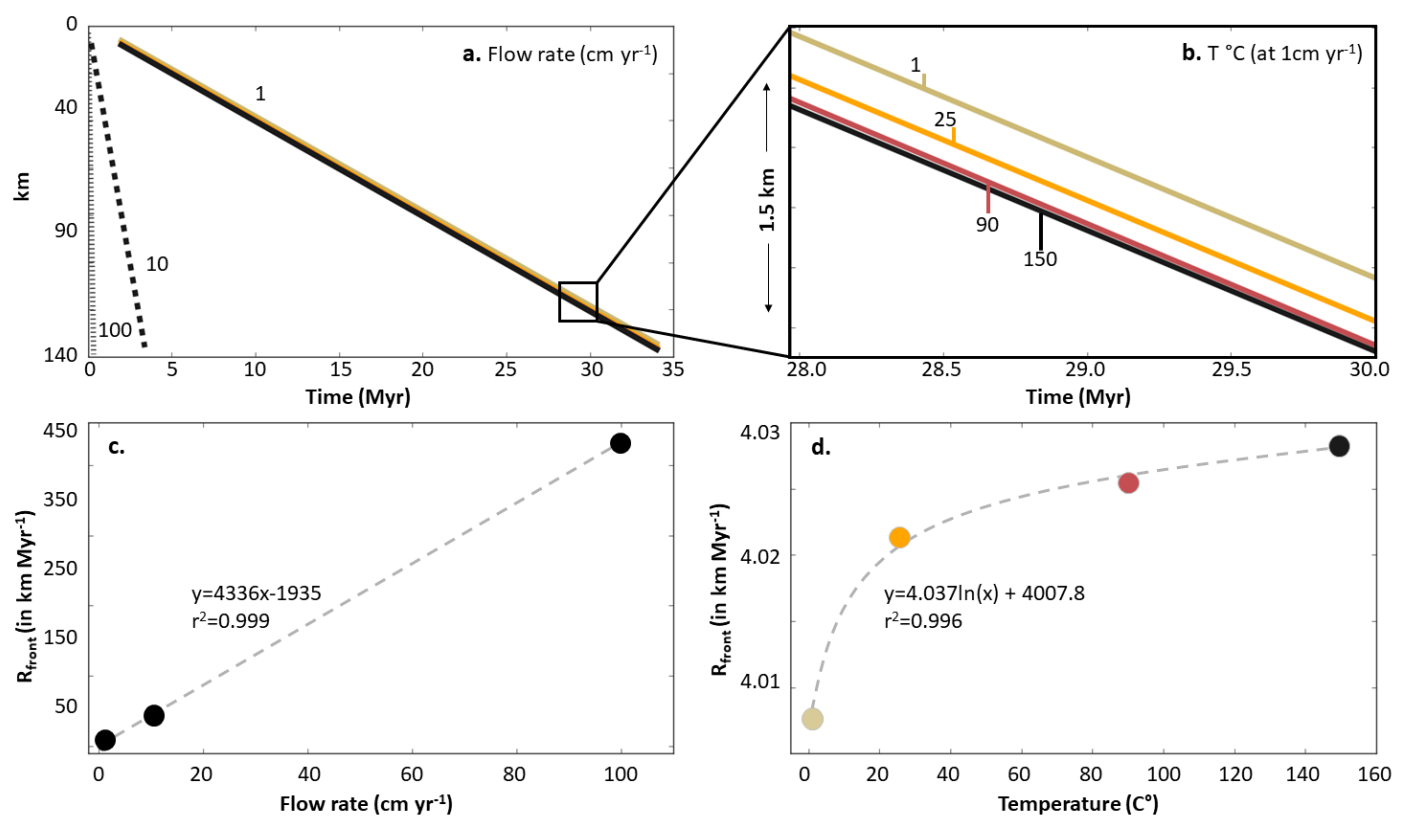

Fig. 4: a. Depth of the alteration front as a function of time, where the depth is defined by the trailing edge of the alteration front $\left(T=150{ }^{\circ} \mathrm{C}\right.$ for flow rate $=100$ and flow rate $=10$

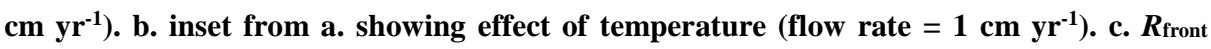
regressed over flow rate. $d$. $R$ front regressed over temperature.

The fixed temperatures and flow rates used here over the entire column length allow us to evaluate the effect of these parameters on the time window of active olivine alteration. In reality, temperature and flow rate are expected to vary with depth and time during Enceladus' evolution (Czechowski \& Witek, 2015; Malamud \& Prialnik, 2013). In upwelling fluid pathways a thermal gradient from seafloor to core center may vary by up to $10{ }^{\circ} \mathrm{C}$, and slower fluid pathways during downwelling may have thermal gradients up to $100{ }^{\circ} \mathrm{C}$ (Choblet et al., 2017). Because of this, $t_{\mathrm{d}}$ may be overestimated by model cases that adopt low temperatures and slow water velocities throughout the 
entire column, and correspondingly underestimated by high-temperature, fast-flow rate model cases. The longest and shortest windows of active serpentinization in the model cases are respectively $t_{\mathrm{d}}=60 \mathrm{Myr}$ and $t_{\mathrm{d}}=380,000$ years (Table 2), These windows can then be considered end-member timescales that would encompass total serpentinization times of columns that included temperature or water velocity gradients.

Considering weathering along a circuit from seafloor to core and back to seafloor (Fig. 1), the limiting factor in the time needed to totally alter the core will be determined by the downwelling path due to slower water velocities (Fig. 1 and Table 2). The existence of upwelling fluids is dependent on there being enough downwelling fluid remaining, which is then heated in the core to create a hydrothermal upwelling fluid. While there is a high percentage of unaltered olivine remaining, the entire core would experience downwelling fluid circulation until some minimum water-filled porosity is established throughout the core. At that point, downwelling through the core and upwelling through fracture pathways at the poles can occur simultaneously, as considered in hydrodynamic models of water circulation in the core (Choblet et al., 2017; Liao et al., 2020) and as in the circuit described above. Upwelling paths in any circuit will then alter faster than their respective downwelling circuits, as they are subject to higher temperatures and higher water flow rates (Table 2). Therefore, we consider that the downwelling cases represent the maximum $t_{\mathrm{d}}$ for an entire rocky core with a radius equal to the column length.

\subsection{Model limitations}

The dependency of $t_{\mathrm{d}}$ on the formation and propagation of an alteration front shows the importance of considering geochemical reactions over long distances, rather than applying small-scale models to macroscale processes. In the $140 \mathrm{~km}$ column models, olivine dissolution times were most sensitive to changes in flow rate and initial $\mathrm{O}: \mathrm{W}$ ratios (Fig. 4). In contrast, the results of sensitivity analyses using a column comprising only a single $40 \mathrm{~m}$ cell (with $\mathrm{O}: \mathrm{W}=4: 1$, grain size $=0.1 \mathrm{~mm}$ ) show that the time required for total olivine dissolution $\left(t_{\mathrm{d}}\right)$ is identical for flow rates at or above $1 \mathrm{~cm} \mathrm{yr}^{-1}$ (Fig. 6a). Tests with a $0.1 \mathrm{~cm} \mathrm{yr}^{-1}$ flow rate show that the residence time in a single cell 
at this flow rate (40,000 years) is long enough that the increased $\mathrm{pH}$ and decreased water activity noticeably affect decrease the olivine dissolution rate. Even in this case, however, $t_{\mathrm{d}}$ in the single-cell column is more sensitive to changes in temperature than changes in flow rate. Similarly, in a single cell, $t_{\mathrm{d}}$ is more sensitive to temperature than initial O:W ratio (Fig. 6b). The differences in the results based on the parameters used in a single-cell or batch reactor model, when compared to the importance of the same parameters in the $140 \mathrm{~km}$ model, highlights the importance of incorporating reactive transport modeling into interpretations of water-rock interactions in satellites.

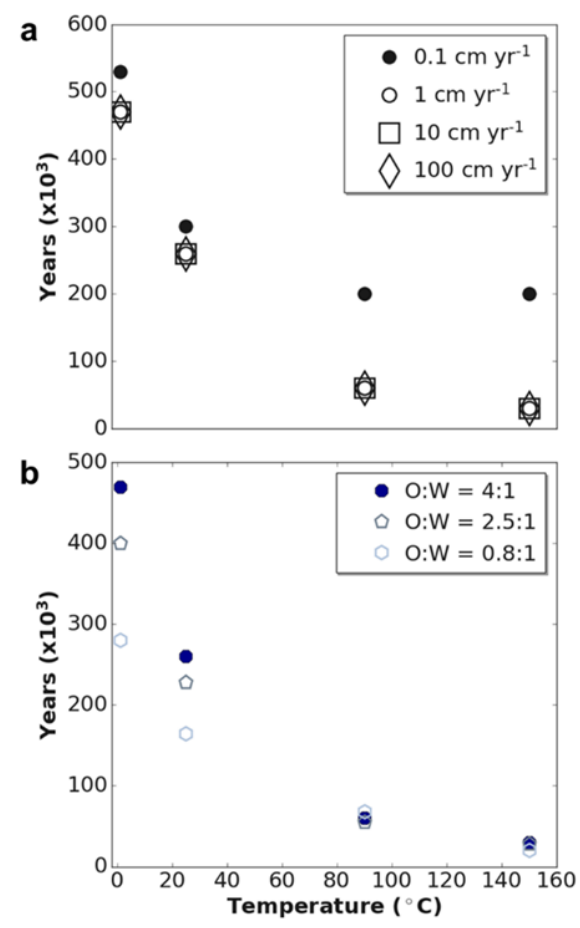

Fig. 6: effect of a. flow rate and b. initial $O: W$ ratio on olivine alteration in a single cell. "Years $\left(\times 10^{3}\right)$ " indicates the reaction time necessary to dissolve all olivine in the cell.

While modelling geochemical reactions over kilometer-scale distances provides insight into global processes, the use of the 1-D transport model requires necessary simplifications to water-rock interaction processes that would presumably occur in the core. Notably, volume increases of the solid phase during serpentinization are not 
considered by the code. In our model outputs the total calculated mass of precipitated secondary minerals would represent a volume increase of more than $30 \%$ compared to the initial olivine. These volume increases have been shown to drive reaction-induced cracking that can increase serpentinization times in batch reactions by up to an order of magnitude (Malvoisin et al., 2017). Similar reaction-induced fracturing has been proposed to form a reaction front that can advance at rates of tens of $\mathrm{m} \mathrm{yr}^{-1}$ in a peridotite having just $1 \%$ preexisting fracture porosity (Kelemen et al., 2011; Rudge et al., 2010). Because the porosity of Enceladus' core is up to two orders of magnitude greater than porosities in terrestrial peridotites (0.8\%, Hyndman and Drury 1976) and as the slowest imposed flow rate of $1 \mathrm{~cm} \mathrm{yr}^{-1}$ in our models is slower than the alteration front propagation anticipated from reaction-induced cracking, the addition of reactioninduced cracking to our model would be expected to accelerate $R_{\text {front }}$ and increase the global serpentinization rate.

Another simplification in our model is that olivine dissolution and precipitation of secondary phases are treated as two separate steps. This ignores any effect of dissolution-precipitation coupling, which has been suggested to decrease long-term olivine dissolution rates by up to four orders of magnitude in acidic fluids (Daval et al., 2011). However, in alkaline fluids, this same coupled dissolution-precipitation mechanism during serpentinization may in fact drive microfracturing at the olivine surface and promote olivine alteration (Lafay et al., 2018; Plümper et al., 2012). In light of these complexities, general quantitative models of how this factor influences dissolution rates over time are not readily available. Speculative inhibition of the dissolution rate over time is approximated by the aging term of Eq. 5, which decreases the rate by up to two orders of magnitude during runs.

\subsection{Implications for Enceladus' core evolution}

Despite the simplifying assumptions inherent to our model, the results are consistent with timescales of similar processes observed on Earth. The maximum $t_{\mathrm{d}}$ of olivine alteration in Enceladus' core based on our results would be 35-60 Myr (Table 2). This range overlaps the estimate of 54-240 Myr for serpentinization of a core the size of 
Enceladus' using the peridotite weathering rates proposed by Früh-Green et al. (2003).

That our estimates are somewhat shorter is unsurprising given that we assume a porous, water-saturated core with a mechanism for active water flow within, as opposed to the low-porosity peridotite massifs that the terrestrial estimates are based from. Furthermore, our results are comparable to the timescales obtained by Malamud and Prialnik (2016) for reaching an almost complete core serpentinization during the early evolution of Enceladus. However, for the case of serpentinization that started early on during Enceladus' history, all olivine should have been exhausted now, and associated $\mathrm{H}_{2}$ production by serpentinization should be extremely low. This suggests either that Enceladus formed very late, and/or that ice melting and hence water circulation have not developed until recently.

A comparison of the time windows of active $\mathrm{H}_{2}$ production from our 1-D model with the amount of $\mathrm{H}_{2}$ currently emitting from Enceladus can be used to estimate the maximum age of active water-rock interaction. The formation of an alteration front during reactive transport retards the rate of olivine alteration in the core. This means that the longest time windows of active olivine serpentinization are in scenarios with delayed alteration front formation and slow alteration front propagation. Olivine alteration times and corresponding $\mathrm{H}_{2}$ production for the longest alteration cases (with $\mathrm{O}: \mathrm{W}=4: 1, \mathrm{~T}=1^{\circ} \mathrm{C}$, flow rate $=1 \mathrm{~cm} \mathrm{yr}^{-1}$ ) are shown in Fig. 5 for all grain sizes. Complete alteration of all of the olivine in the core is achieved in 35, 37, and $58 \mathrm{Myr}$ for grain sizes of $0.1 \mathrm{~mm}$ (case 1, Fig. 5a), $1 \mathrm{~mm}$ (case 4, Fig. 5b), and $5 \mathrm{~mm}$ (case 5, Fig. 5c), respectively. Thus, the slowest end-member case for alteration of the initial olivine, the window of $\mathrm{H}_{2}$ production is just under 60 million years. During the entire $58 \mathrm{Myr}$ period, $\mathrm{H}_{2}$ production is several orders of magnitude larger than the minimum $\mathrm{H}_{2}$ release rate calculated from the observed $\mathrm{H}_{2}$ in the plume $\left(1-5 \times 10^{9}\right.$ moles $\mathrm{yr}^{-1}$, Waite et al. 2017). During alteration of the initial olivine in the initial stage of water-rock interaction $\mathrm{H}_{2}$ production rates peak at $3.5 \times 10^{13}$ moles $\mathrm{yr}^{-1}$, and subsequently plateau at over $2 \times 10^{12}$ moles $\mathrm{yr}^{-1}$ as the alteration front propagates through the column (Fig. $5 d-f)$. It is notable that in these models, decreasing the amount of initial olivine must decrease the total amount of $\mathrm{H}_{2}$ produced, but it does not affect the rate of $\mathrm{H}_{2}$ production. For example, case 2 (identical to 1, except for an initial $\mathrm{O}: \mathrm{W}=2.5: 1$ ) also has $\mathrm{H}_{2}$ production rates that initially peak to $>1 \times 10^{13}$ moles $\mathrm{yr}^{-1}$ and plateau at over 2 
$\times 10^{12}$ moles $\mathrm{yr}^{-1}$, but olivine is completely exhausted within $6 \mathrm{Myr}$ (Table 2) The result based on less initial olivine present in the column relative to water-filled porosity, which is analogous to starting with a partially altered rock phase, is that $\mathrm{H}_{2}$ is produced at the same global annual rate only for a fraction of the time.
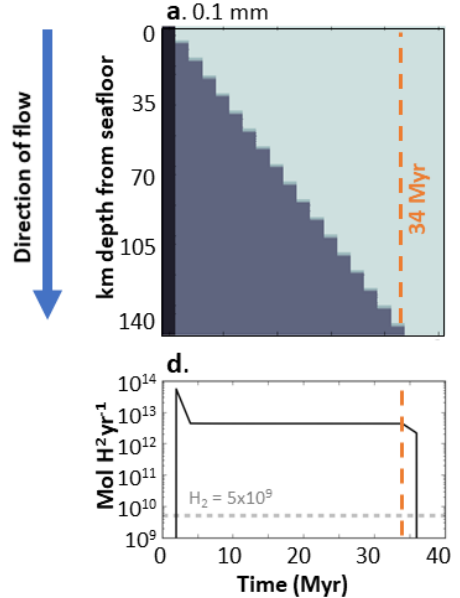
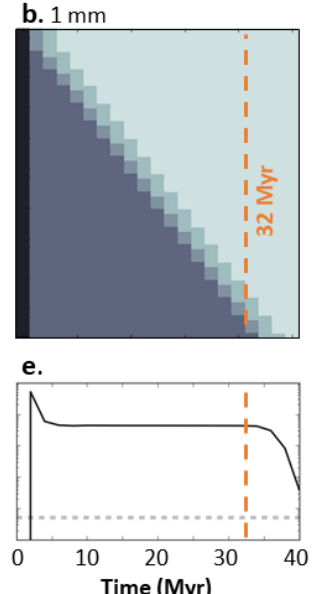
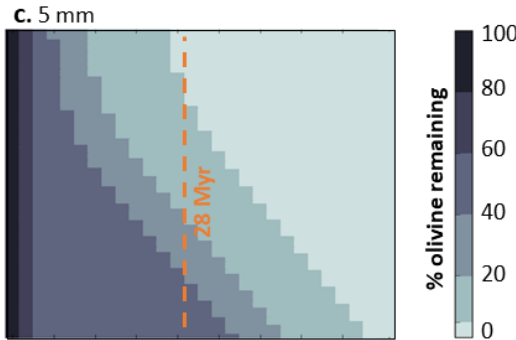

f.

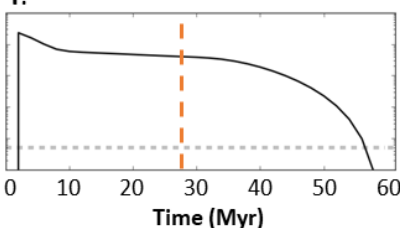

Fig. 5: Depth profiles of olivine dissolution and calculated global $\mathrm{H}_{2}$ production as a function of time for a. grain size $=0.1 \mathrm{~mm}$. b. grain size $=1 \mathrm{~mm}$ and c. grain size $=5 \mathbf{m m}$. Vertical dashed line indicates the time the leading edge of the alteration front reaches the column terminus. Panels d-f show the global $\mathrm{H}_{2}$ production over the time corresponding to each of the cases above. Note the initial period of water-rock reaction is reflected in an initial spike in $\mathrm{H}_{2}$ production. Horizontal dashed line indicates minimum global $\mathrm{H}_{2}$ release rates from Enceladus.

To constrain our output to cases that might best reflect current processes in Enceladus, the model output and implications can be compared to the low core density and $\mathrm{H}_{2}$ emission rates inferred from the data collected by the Cassini mission. We can evaluate the hypothesis that $\mathrm{H}_{2}$ emitted from Enceladus is evidence of active primary mineral alteration by reviewing model scenarios where $\mathrm{H}_{2}$ production occurs in a watersaturated column - where the column is not dominated by the water-limited sector as described in Fig. 2. Contemporaneous $\mathrm{H}_{2}$ production and water-filled porosity over the entire column length can occur in the 1-D reaction transport column in 4 scenarios: 1. imposed flow rates that always exceed the olivine dissolution rate (not modelled here, 
but as we discuss below, physically not possible); 2 . low initial olivine percentage or large grain sizes that prevent the formation of an alteration front (cases 3 and 5, respectively); 3 . in the initial phase of every run where the initial water-filled porosity interacts with the initial olivine (all cases); 4. during a period of time after an alteration front progresses through the entire column to intersect the outflow cell (cases 1, 2, 4, and 6-10). In our models, the $1^{\text {st }}$ scenario requires a flow rate of more than $100,000 \mathrm{~cm}$ $\mathrm{yr}^{-1}$, which is not consistent with the physical constraints prescribed by tidal heating mechanisms (Choblet et al., 2017). Scenarios 2-4 are explored in our models and can be compared to observations of Enceladus' density and current global $\mathrm{H}_{2}$ production.

The $2^{\text {nd }}$ scenario is described in our models by either a low initial olivine percentage available for dissolution or by low olivine specific surface area. A low initial olivine percentage (initial $\mathrm{O}: \mathrm{W}=0.8: 1$ ) completely prevents the formation of an alteration front even at slow reaction conditions (grain size $=0.1 \mathrm{~mm}, \mathrm{~T}=1^{\circ} \mathrm{C}$, flow rate $=1 \mathrm{~cm} \mathrm{yr}^{-1}$, case 3). At such a low O:W ratio, olivine dissolves before the available mass of water is completely consumed by secondary reactions. This process is relatively rapid and all of the primary olivine in the core is totally exhausted after 380,000 years of reaction time (Fig. 3d). On the other hand, olivine with low specific surface area delays the production of an alteration front. At large grain sizes (5 $\mathrm{mm}$, case 5), water flow continues through the column contemporaneously with olivine dissolution for $\sim 30 \mathrm{Myr}$ before the formation of an alteration front. However, $5 \mathrm{~mm}$ is much larger than the reported average radius of chondritic olivine chondrules (0.1-0.2 mm, Rubin 1989) and even with moderate grain sizes ( $1 \mathrm{~mm}$, case 4$)$ an alteration front forms after only 2 Myr of reaction time (Fig. 5c).

The $3^{\text {rd }}$ scenario is a feature of the initial alteration period, analogous to the initial water-rock interaction period defined by first contact of primary olivine with liquid water. This initial alteration period is marked by active olivine dissolution as well as water-filled porosity throughout the column. Ultimately, the $\mathrm{H}_{2}$ production in this period is markedly high. Vigorous olivine alteration causes global $\mathrm{H}_{2}$ production rates to reach values as high as $3-5 \times 10^{13}$ moles $\mathrm{yr}^{-1}$ before an alteration front forms (Fig. $5 \mathrm{~d}$ f), which is significantly higher than the calculated minimum global $\mathrm{H}_{2}$ release rate from Enceladus (1-5 $\times 10^{9}$ moles $\mathrm{yr}^{-1}$, Waite et al. 2017). Overall, this period is geologically brief, as the column becomes mostly anhydrous and an alteration front is 
formed within 2 Myr. During this transient initial stage, the time span during which the modest rates of observed $\mathrm{H}_{2}$ release from Enceladus are produced in the column is extremely short-lived in all models, making this scenario rather unlikely.

The $4^{\text {th }}$ scenario corresponds to model cases $1,2,4$, and 6-10 at the end of the run where the alteration front has progressed through the entire column so that it is near to, or intersecting, the end of the column. The time at which the alteration front reaches the end of the column is indicated in Fig. 5 as an orange dashed line. In the examples shown in Fig. 5 this corresponds to the last several million years of reaction time, where the majority of the column is composed of secondary hydrous minerals and the alteration front has reached the last part of the core (Fig. 5a-c, after $25 \mathrm{Myr}$ ). This scenario is also most consistent with estimated annual $\mathrm{H}_{2}$ release from Enceladus of $1 \times 10^{9}$ moles $\mathrm{yr}^{-1}$ : after the leading edge of the alteration front reaches the end of the column, $\mathrm{H}_{2}$ production decreases over several Myr from a plateau of $2 \times 10^{12}$ moles $_{\mathrm{yr}^{-1}}$ to zero after all olivine in the column is dissolved (Fig. $5 \mathrm{~d}-\mathrm{f}$ ). The time window between the time where the alteration front first bisects the final cell of the column and $t_{\mathrm{d}}$ is dependent on the shape and the propagation rate of the alteration front. Considering an example case with a very diffuse sigmoidal alteration front and a slow $R_{\text {front }}$ (case $5, \mathrm{O}: \mathrm{W}=4: 1$, grain size $=5 \mathrm{~mm}, \mathrm{~T}=1{ }^{\circ} \mathrm{C}$, flow rate $=1 \mathrm{~cm} \mathrm{yr}^{-1}$ ), the alteration front reaches the outflow cell at $\sim 26 \mathrm{Myr}$ and $t_{\mathrm{d}}=58 \mathrm{Myr}$ (Fig. 5c). This represents $32 \mathrm{Myr}$ of contemporaneous fluid flow throughout the entire column and active $\mathrm{H}_{2}$ production. Again, case 5 is an endmember example. Even decreasing the grain radius to $1 \mathrm{~mm}$ at the same conditions (case $4, \mathrm{O}: \mathrm{W}=4: 1$, grain radius $=5 \mathrm{~mm}, \mathrm{~T}=1^{\circ} \mathrm{C}$, flow rate $=1$

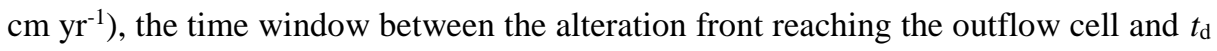
decreases to $\sim 6$ Myr (Fig. 5b). This time window would be further shortened by increases in the propagation rate or a narrowing of the width of the alteration front (as a result of decreasing the initial $\mathrm{O}: \mathrm{W}$ ratio, increasing the temperature, or increasing the flow rate).

According to our simulations, in both plausible scenarios (2 and 4$)$ the current low $\mathrm{H}_{2}$ release production rate from Enceladus thereby implies that olivine alteration in the core is very close to completion, if not already at completion (Fig. 5d-f). As aqueous alteration is very rapid $\left(t_{\mathrm{d}}<4 \mathrm{Myr}\right)$ in upwelling regions characterized by fast flow and elevated temperature, it is very likely that the olivine in these regions has long since 
been altered to secondary phases. The $\mathrm{H}_{2}$ that we measure today in the plumes is then more likely to have been generated in the coldest parts of the rock core during downwelling (Fig. 6). This apparently contrasts with the model of $\mathrm{H}_{2}$ generation in Enceladus proposed by Glein et al. (2018) and Glein \& Waite, (2020) who concluded that the observed $\mathrm{H}_{2}$ must be largely sourced by rocks at $250-350{ }^{\circ} \mathrm{C}$ in the deep core. This conclusion is not necessarily at odds with our results: as discussed for scenario 4 above, our model also suggests that if alteration is still ongoing it is more likely to be generated within the deeper part of the core (Fig. 5 d-f, Fig. 6). In addition, fluid circulation through a core with very low permeability $\left(<10^{-16} \mathrm{~m}^{2}\right)$ may generate temperatures of $>200^{\circ} \mathrm{C}$ when reaching the core center (Choblet et al., 2017). However, as olivine alteration rates increase with $\mathrm{T}$ until $250-310{ }^{\circ} \mathrm{C}$ (Lamadrid et al., 2020; Malvoisin et al., 2012; Wegner \& Ernst, 1983), $t_{\mathrm{d}}$ in this case would be shorter than predicted by our models. We also note that the model of Glein et al. (2018) assumes that the fluid in the deep core is in redox equilibrium with serpentinizing mafic silicates, whereas the fluid nearer the seafloor is in redox equilibrium with secondary carbonate minerals. This is also consistent with our conclusion that seafloor alteration would occur rapidly, and current production is sourced from within an alteration front that has progressed to the inner core with downwelling fluid (Fig. 6) 


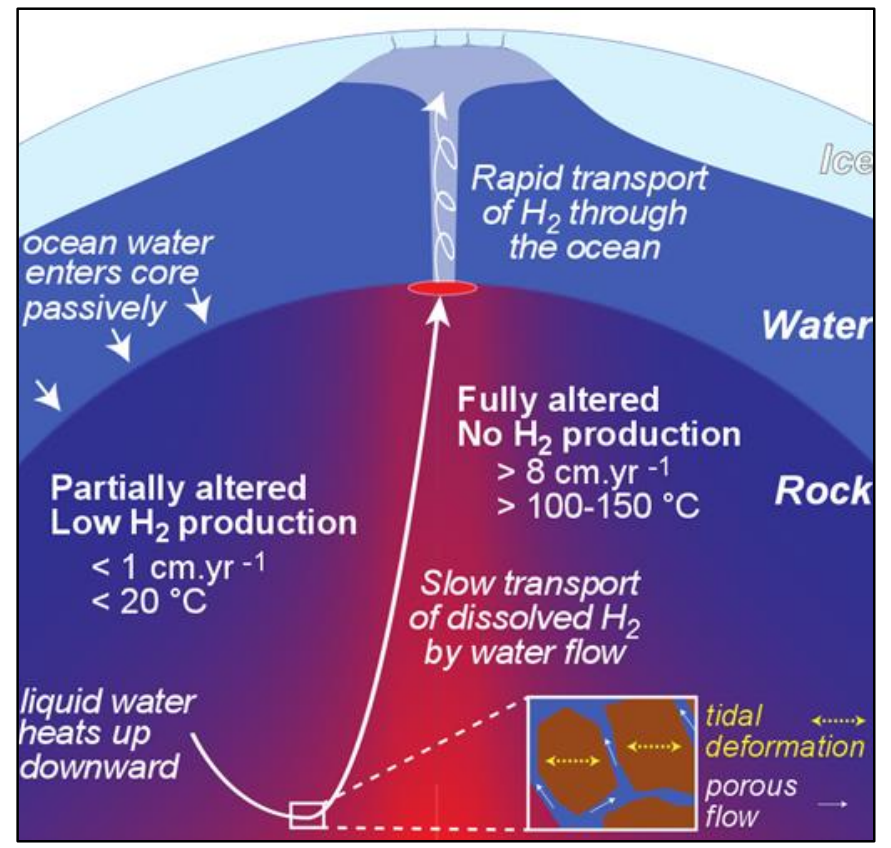

Fig. 6: Conceptual sketch illustrating the fluid flow-driven chemical alteration and the resulting $\mathrm{H}_{2}$ production and transport in Enceladus' porous core (adapted from Choblet et al. 2017). Most of the present $\mathrm{H}_{2}$ production is expected to occur during downwelling (flow

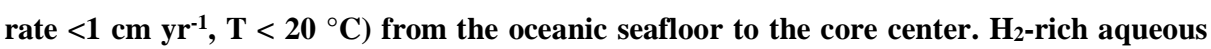
fluids progressively heat up in the deep core due to tidal heating, until they become thermally unstable and rise, most notably in the polar regions, in the form of rapid hot water upwelling (flow rate $>8 \mathrm{~cm} \mathrm{yr}^{-1}, \mathrm{~T}>100^{\circ} \mathrm{C}$ ). Hot water outflows are responsible for seafloor hotspots triggering oceanic thermal plumes that then transport $\mathrm{H}_{2}$ rapidly to the jet sources in the ice shell. The whole cycle between the production of $\mathrm{H}_{2}$ in cold regions and the release at the surface could take several millions of years.

Finally, it might also be possible that primary minerals are totally exhausted at present and that the observed $\mathrm{H}_{2}$ is being produced by another process or is released over time from a previous production stage. For example, Glein et al. (2018) showed that the production of $\mathrm{H}_{2}$ by organic pyrolysis can explain the observed $\mathrm{H}_{2}$ given a high total tidal power within the core (>50 GW). As for $\mathrm{H}_{2}$ release over time, the observed high $\mathrm{H}_{2}: \mathrm{CH}_{4}$ ratios are thought to indicate that long-term $\mathrm{H}_{2}$ storage is not occurring within Enceladus (Waite et al., 2017). However, the possibility of $\mathrm{H}_{2}$ release from the 
core after active $\mathrm{H}_{2}$ production has ceased is still possible by a process of flushing $\mathrm{H}_{2}$ enriched fluids out of the porous core by fluid transport. During downwelling, the $\mathrm{H}_{2}$ concentration increases in the aqueous fluid as olivine alteration proceeds. Warm aqueous fluids, enriched in $\mathrm{H}_{2}$, then become unstable and rise preferentially at the poles to feed seafloor hotspots as illustrated in the conceptual model of Fig. 6. According to the simulations of Choblet et al. (2017), the fluid velocity in hot upwellings is estimated between 8 and $80 \mathrm{~cm} \mathrm{yr}^{-1}$, for a rock permeability of $10^{-14}-10^{-13} \mathrm{~m}^{2}$ and a total tidal power between 10 and $30 \mathrm{GW}$. This would imply transport timescales from the center to the seafloor ranging from 0.2 to $2 \mathrm{Myr}$. As a consequence, it is possible that the $\mathrm{H}_{2}$ being ejected into space today was produced a few millions of years ago and is not currently being produced. Considering the typical time for fluid parcels to go through the cold parts of the rock core during downwelling, today's $\mathrm{H}_{2}$ may even have been produced $\sim 10$ Myr ago.

Taken together, these results indicate that the duration of active hydrothermalism on Enceladus, involving production of $\mathrm{H}_{2}$, is less than $100 \mathrm{Myr}$. The possibility of several successive hydrothermal episodes throughout the moon's history cannot be ruled out, with active hydrothermal stages whose cumulated duration is a few tens of Myr, interspersed by quiescent periods. The general trend of Saturn's moons' orbital expansion is nevertheless more consistent with a single stage of enhanced production of tidal power, involving the formation of an internal ocean and porous flow in the rocky core. While our results do not provide any constraints on the age of Enceladus, they suggest that the existence of global ocean and the water circulation in the porous core is geologically young, less than 100 Myr old.

\subsection{Implications beyond Enceladus' core}

The rates of propagation of the alteration front (Table 2) may also be applied to calculate alteration timescales within a longer or shorter column, this being equivalent to changing the radius of the core. For all model cases with a $1 \mathrm{~cm} \mathrm{yr}^{-1}$ flow rate (e.g. case $6, \mathrm{O}: \mathrm{W}=4: 1$, grain size $=0.1 \mathrm{~mm}, \mathrm{~T}=25^{\circ} \mathrm{C}$ ) the alteration front progresses at approximately $4 \mathrm{~km} \mathrm{yr}^{-1}$ (Fig. $4 \mathrm{c}$ ). These alteration rates can then be adapted to the 
range of estimates for the radius Enceladus core, which vary from 185-190 km (Beuthe et al., 2016; Čadek et al., 2016; Hemingway et al., 2018). This gives a range of timescales of active serpentinization of 50-75 Myr given the propagation rates reported in Table 2. Additionally, we note that these rates could be adapted to estimate the duration of active serpentinization on other icy satellites where there is evidence of a past or current liquid ocean and an inner rocky core. For example, a column with a length consistent with the hypothesized rocky core of Saturn's smaller moon Mimas (< $100 \mathrm{~km}$ radius, Noyelles et al., 2019) would be totally serpentinized within $25 \mathrm{Myr}$. However, for satellites where current observations or models do not adequately constrain the physical parameters of water flow velocities within a core, these estimates remain speculative.

In icy satellites that do not experience tidally induced water flow throughout a rocky core, mechanical- or reaction-induced fracturing becomes particularly important. During alteration, the creation of void space where secondary mineral volume does not completely replace the water volume lost in hydration reactions may result in potentially irreversible core compaction (Malamud \& Prialnik, 2016). This may leave fracturing as the main driver of introducing water from any liquid ocean to the core, rather than passive water flow through porous, unconsolidated media. Hydrothermal models of the dwarf planet Ceres (Neveu et al., 2015) and the Kuiper belt object Orcus (Malamud \& Prialnik, 2015) suggest timescales of fracture propagation over time and maximum depths of fracturing within the rocky cores. The propagation rates described in these models are on the order of billions of years, timescales at which the reactions as described in our models would be instantaneous.

\section{Conclusions}

Using a 1-D reactive transport model, we simulated the serpentinization of Enceladus' core using olivine as an analog mineral. We investigated the effect of initial olivine percentage, grain size, temperature, and flow rate on the total time needed to completely alter the primary olivine in a rocky core the size and density of Enceladus'. In most cases, the alteration of olivine results in precipitation of hydrous secondary 
minerals and the formation of an alteration front that slows olivine alteration. For high (4:1) or medium (2.5:1) olivine:water ratios, representative of Enceladus' core, we have shown that the time of total olivine alteration is controlled by the rate of the vertical propagation of the alteration front, which separates a completely altered upstream sector from a water-limited downstream sector with little ongoing alteration. Active olivine dissolution and precipitation of secondary minerals starts at the leading edge of the alteration front.

Longer serpentinization times are obtained for slower fluid flow rates, lower temperatures and larger grain sizes. As a consequence, timescales of olivine alteration in regions characterized by rapid upwelling of hot water $\left(>8 \mathrm{~cm} \mathrm{yr}^{-1},>100-150{ }^{\circ} \mathrm{C}\right)$ are geologically very short $(<500,000$ year), while in regions where cold water slowly circulates $\left(<1 \mathrm{~cm} \mathrm{yr}^{-1},<20^{\circ} \mathrm{C}\right)$ timescales can be up to $60 \mathrm{Myr}$. The latter falls within the range of expected timespans for alteration of a mass of rock equivalent to Enceladus' rocky core based on chemical alteration rates of terrestrial peridotite massifs (Früh-Green et al., 2003).

In all model cases, olivine alteration results in an annual global rate of production of $>1 \times 10^{12}$ moles $\mathrm{yr}^{-1}$ for almost the entire lifetime of active $\mathrm{H}_{2}$ production. This rate is several orders of magnitude greater than Enceladus' minimum $\mathrm{H}_{2}$ release rate $\left(1 \times 10^{9}\right.$ moles $\mathrm{yr}^{-1}$ ) calculated from the $\mathrm{H}_{2}$ measured in its vapor plumes (Waite et al., 2017). This implies that the present release rate corresponds to the tail end of the active $\mathrm{H}_{2}$

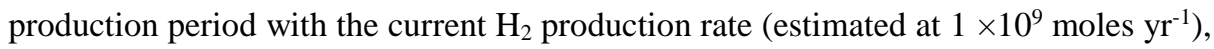
compatible with exhaustion or quasi-exhaustion of the initial stock of olivine. In our models such low $\mathrm{H}_{2}$ production is consistent with cases that either start with a small initial stock of unaltered olivine in the rock (olivine:water volume ratio $<0.8: 1$, or $<20$ vol. \% olivine in the rock phase). Alternatively, this low $\mathrm{H}_{2}$ production may also correspond to the final stages of the alteration process where the alteration front has progressed through the majority of the column (Figs. 3, 5). The conclusion that alteration is nearing completion is also consistent with the inferred low density of Enceladus' core, as olivine is assumed to be replaced by lower-density, hydrous secondary minerals during alteration. Taken together, these results suggest that the liquid ocean on Enceladus is geologically young, developing during the last $100 \mathrm{Myr}$. If the $\mathrm{H}_{2}$ currently being emitted from Enceladus can be positively attributed to 
inorganic production, the results of this study can further serve to constrain the possible length of time that the liquid ocean has existed on Enceladus.

A recent and short-lived duration of hydrothermalism on Enceladus does not reduce the astrobiological interest of this moon. The fact that the hydrothermal activity is recent on Enceladus indeed offer a unique opportunity to study hydrothermal environments during the early stage of planetary evolution. The hydrothermal activity observed today on Enceladus, even if declining, may be representative of various hydrothermal systems that may have active in many other icy bodies. Understanding the chemical complexity emerging in this young hydrothermal system is highly relevant to test the hypothesis that life possibly originated in alkaline hydrothermal vents on Hadean Earth (Martin \& Russell, 2007; Russell et al., 2014; Sojo et al., 2016). Even if the geodynamic context on Enceladus is very different from Hadean Earth, Enceladus provides an independent test on the origin of life in hydrothermal environments, which may be addressed by future exploration missions (Choblet \& Tobie, 2020). Infra-red mapping of Enceladus' surface revealed that outside the currently active south polar terrain, at least one other region in the northern hemisphere has been recently active (Robidel et al., 2020). This area may be the surface expression of another seafloor hotspot and may preserve chemical signatures of recent hydrothermal activities. Future characterization of the south polar plume activity together with compositional mapping of other recently active centers, such as the one recently identified by Robidel et al. (2020), may provide key insights on how hydrothermal activities involved through time and affected the chemical evolution of Enceladus's ocean.

\section{Acknowledgements}

This study acknowledges the financial support from the French Agence Nationale de Recherche, project ANR OASIS (grant $\mathrm{N}^{\circ}$ ANR-16-CE31-0023-01). Laurent Truche acknowledges support from the Institut Universitaire de France. Benjamin Malvoisin is warmly thanked for fruitful discussions over the course of this study. 


\section{References}

Appelo, C. A. J., \& Postma, D. (2004). Geochemistry, groundwater and pollution. CRC press.

Arndt, N. (2011). Geothermal Gradient. In M. Gargaud, R. Amils, J. C. Quintanilla, H. J. (Jim) Cleaves, W. M. Irvine, D. L. Pinti, \& M. Viso (Eds.), Encyclopedia of Astrobiology (pp. 662-662). Springer Berlin Heidelberg. https://doi.org/10.1007/978-3-642-11274-4_643

Baillié, K., Noyelles, B., Lainey, V., Charnoz, S., \& Tobie, G. (2019). Formation of the Cassini Division-I. Shaping the rings by Mimas inward migration. Monthly Notices of the Royal Astronomical Society, 486(2), 2933-2946.

Bandstra, J. Z., Buss, H. L., Campen, R. K., Liermann, L. J., Moore, J., Hausrath, E. M., Navarre-Sitchler, A. K., Jang, J.-H., \& Brantley, S. L. (2008). Compilation of mineral dissolution rates. Kinetics of Water-Rock Interaction, 737-823.

Běhounková, M., Tobie, G., Choblet, G., \& Čadek, O. (2012). Tidally-induced melting events as the origin of south-pole activity on Enceladus. Icarus, 219(2), 655664.

Beuthe, M., Rivoldini, A., \& Trinh, A. (2016). Enceladus's and Dione's floating ice shells supported by minimum stress isostasy. Geophysical Research Letters, 43(19), 10-088.

Browning, L. B., McSween Jr, H. Y., \& Zolensky, M. E. (1996). Correlated alteration effects in CM carbonaceous chondrites. Geochimica et Cosmochimica Acta, $60(14), 2621-2633$. 
Buseck, P. R., \& Goldstein, J. I. (1969). Olivine compositions and cooling rates of pallasitic meteorites. Geological Society of America Bulletin, 80(11), 21412158.

Čadek, O., Souček, O., Běhounková, M., Choblet, G., Tobie, G., \& Hron, J. (2019). Long-term stability of Enceladus' uneven ice shell. Icarus, 319, 476-484.

Čadek, O., Tobie, G., Van Hoolst, T., Massé, M., Choblet, G., Lefèvre, A., Mitri, G., Baland, R.-M., Běhounková, M., \& Bourgeois, O. (2016). Enceladus’s internal ocean and ice shell constrained from Cassini gravity, shape, and libration data. Geophysical Research Letters, 43(11), 5653-5660.

Charnoz, S., Crida, A., Castillo-Rogez, J. C., Lainey, V., Dones, L., Karatekin, Ö., Tobie, G., Mathis, S., Le Poncin-Lafitte, C., \& Salmon, J. (2011). Accretion of Saturn's mid-sized moons during the viscous spreading of young massive rings: Solving the paradox of silicate-poor rings versus silicate-rich moons. Icarus, 216(2), 535-550.

Choblet, G., \& Tobie, G. (2020). Enceladus as a potential oasis for life: Science goals and investigations for future explorations. Experimental Astronomy.

Choblet, G., Tobie, G., Sotin, C., Běhounková, M., Čadek, O., Postberg, F., \& Souček, O. (2017). Powering prolonged hydrothermal activity inside Enceladus. Nature Astronomy, 1(12), 841.

Christoffersen, M. R. (1976). The kinetics of dissolution of calcium sulphate dihydrate in water. Journal of Crystal Growth, 35(1), 79-88.

Collins, G. C., \& Goodman, J. C. (2007). Enceladus' south polar sea. Icarus, 189(1), $72-82$. 
Crida, A., \& Charnoz, S. (2012). Formation of regular satellites from ancient massive rings in the solar system. Science, 338(6111), 1196-1199.

Crida, A., Charnoz, S., Hsu, H.-W., \& Dones, L. (2019). Are Saturn's rings actually young? Nature Astronomy, 1-4.

Ćuk, M., Dones, L., \& Nesvorný, D. (2016). Dynamical evidence for a late formation of Saturn's moons. The Astrophysical Journal, 820(2), 97.

Czechowski, L., \& Witek, P. (2015). Comparison of early evolutions of Mimas and Enceladus. Acta Geophysica, 63(3), 900-921.

Daval, D., Sissmann, O., Menguy, N., Saldi, G. D., Guyot, F., Martinez, I., Corvisier, J., Garcia, B., Machouk, I., \& Knauss, K. G. (2011). Influence of amorphous silica layer formation on the dissolution rate of olivine at $90 \mathrm{C}$ and elevated pCO 2. Chemical Geology, 284(1), 193-209.

Dixon, D. G., \& Hendrix, J. L. (1993). Theoretical basis for variable order assumption in the kinetics of leaching of discrete grains. AIChE Journal, 39(5), 904-907.

Farough, A., Moore, D. E., Lockner, D. A., \& Lowell, R. (2016). Evolution of fracture permeability of ultramafic rocks undergoing serpentinization at hydrothermal conditions: An experimental study. Geochemistry, Geophysics, Geosystems, $17(1), 44-55$.

Frost, B. R., \& Beard, J. S. (2007). On silica activity and serpentinization. Journal of Petrology, 48(7), 1351-1368.

Früh-Green, G. L., Kelley, D. S., Bernasconi, S. M., Karson, J. A., Ludwig, K. A., Butterfield, D. A., Boschi, C., \& Proskurowski, G. (2003). 30,000 years of hydrothermal activity at the Lost City vent field. Science, 301(5632), 495-498. 
Fuller, J., Luan, J., \& Quataert, E. (2016). Resonance locking as the source of rapid tidal migration in the Jupiter and Saturn moon systems. Monthly Notices of the Royal Astronomical Society, 458(4), 3867-3879.

Glein, C. R., Baross, J. A., \& Waite, J. (2015). The pH of Enceladus' ocean. Geochimica et Cosmochimica Acta, 162, 202-219.

Glein, C. R., Postberg, F., \& Vance, S. (2018). The geochemistry of Enceladus: Composition and controls. Enceladus and the Icy Moons of Saturn, 39.

Glein, C. R., \& Waite, J. (2020). The Carbonate Geochemistry of Enceladus' Ocean. Geophysical Research Letters, 47(3).

Hansen, C., Esposito, L., Stewart, A., Colwell, J., Hendrix, A., Pryor, W., Shemansky, D., \& West, R. (2006). Enceladus' water vapor plume. Science, 311(5766), $1422-1425$.

Hansen, C., Shemansky, D. E., Esposito, L. W., Stewart, A., Lewis, B., Colwell, J., Hendrix, A., West, R. A., Waite Jr, J., \& Teolis, B. (2011). The composition and structure of the Enceladus plume. Geophysical Research Letters, 38(11).

Hemingway, D., Iess, L., Tajeddine, R., \& Tobie, G. (2018). The interior of Enceladus. Enceladus and the Icy Moons of Saturn, 57-77.

Hirata, N., Miyamoto, H., \& Showman, A. P. (2014). Particle deposition on the Saturnian satellites from ephemeral cryovolcanism on Enceladus. Geophysical Research Letters, 41(12), 4135-4141.

Holm, N. G., Oze, C., Mousis, O., Waite, J., \& Guilbert-Lepoutre, A. (2015). Serpentinization and the formation of $\mathrm{H} 2$ and $\mathrm{CH} 4$ on celestial bodies (planets, moons, comets). Astrobiology, 15(7), 587-600. 
Hsu, H.-W., Postberg, F., Sekine, Y., Shibuya, T., Kempf, S., Horányi, M., Juhász, A., Altobelli, N., Suzuki, K., \& Masaki, Y. (2015). Ongoing hydrothermal activities within Enceladus. Nature, 519(7542), 207-210.

Hyndman, R., \& Drury, M. (1976). The physical properties of oceanic basement rocks from deep drilling on the Mid- Atlantic Ridge. Journal of Geophysical Research, 81(23), 4042-4052.

Iess, L., Stevenson, D., Parisi, M., Hemingway, D., Jacobson, R., Lunine, J., Nimmo, F., Armstrong, J., Asmar, S., \& Ducci, M. (2014). The gravity field and interior structure of Enceladus. Science, 344(6179), 78-80.

Johnson, J., Anderson, G., \& Parkhurst, D. (2000). Database "thermo. Com. V8. R6. 230," Rev. 1-11. Lawrence Livermore Natl. Lab., Livermore, California.

Kelemen, P. B., Matter, J., Streit, E. E., Rudge, J. F., Curry, W. B., \& Blusztajn, J. (2011). Rates and mechanisms of mineral carbonation in peridotite: Natural processes and recipes for enhanced, in situ $\mathrm{CO} 2$ capture and storage. Annual Review of Earth and Planetary Sciences, 39, 545-576.

Komatsu, M., Krot, A. N., Petaev, M. I., Ulyanov, A. A., Keil, K., \& Miyamoto, M. (2001). Mineralogy and petrography of amoeboid olivine aggregates from the reduced CV3 chondrites Efremovka, Leoville and Vigarano: Products of nebular condensation, accretion and annealing. Meteoritics \& Planetary Science, 36(5), 629-641.

Lafay, R., Montes-Hernandez, G., Janots, E., Chiriac, R., Findling, N., \& Toche, F. (2012). Mineral replacement rate of olivine by chrysotile and brucite under high alkaline conditions. Journal of Crystal Growth, 347(1), 62-72. 
Lafay, R., Montes-Hernandez, G., Renard, F., \& Vonlanthen, P. (2018). Intracrystalline reaction-induced cracking in olivine evidenced by hydration and carbonation experiments. Minerals, $8(9), 412$.

Lainey, V., Casajus, L. G., Fuller, J., Zannoni, M., Tortora, P., Cooper, N., Murray, C., Modenini, D., Park, R. S., \& Robert, V. (2020). Resonance locking in giant planets indicated by the rapid orbital expansion of Titan. Nature Astronomy, $1-6$.

Lainey, V., Jacobson, R. A., Tajeddine, R., Cooper, N. J., Murray, C., Robert, V., Tobie, G., Guillot, T., Mathis, S., \& Remus, F. (2017). New constraints on Saturn's interior from Cassini astrometric data. Icarus, 281, 286-296.

Lainey, V., Karatekin, Ö., Desmars, J., Charnoz, S., Arlot, J.-E., Emelyanov, N., Le Poncin-Lafitte, C., Mathis, S., Remus, F., \& Tobie, G. (2012). Strong tidal dissipation in Saturn and constraints on Enceladus' thermal state from astrometry. The Astrophysical Journal, 752(1), 14.

Lamadrid, H. M., Rimstidt, J. D., Schwarzenbach, E. M., Klein, F., Ulrich, S., Dolocan, A., \& Bodnar, R. J. (2017). Effect of water activity on rates of serpentinization of olivine. Nature Communications, 8, 16107.

Lamadrid, H. M., Zajacz, Z., Klein, F., \& Bodnar, R. (2020). Synthetic fluid inclusions XXIII. Effect of temperature and fluid composition on rates of serpentinization of olivine. Geochimica et Cosmochimica Acta, 292, 285-308.

Leong, J. A. M., \& Shock, E. L. (2020). Thermodynamic constraints on the geochemistry of low-temperature, continental, serpentinization-generated fluids. American Journal of Science, 320(3), 185-235. 
Liao, Y., Nimmo, F., \& Neufeld, J. A. (2020). Heat production and tidally driven fluid flow in the permeable core of Enceladus. Journal of Geophysical Research: Planets.

Malamud, U., \& Prialnik, D. (2013). Modeling serpentinization: Applied to the early evolution of Enceladus and Mimas. Icarus, 225(1), 763-774.

Malamud, U., \& Prialnik, D. (2015). Modeling Kuiper belt objects Charon, Orcus and Salacia by means of a new equation of state for porous icy bodies. Icarus, 246, 21-36.

Malamud, U., \& Prialnik, D. (2016). A 1-D evolutionary model for icy satellites, applied to Enceladus. Icarus, 268, 1-11.

Malvoisin, B., Brantut, N., \& Kaczmarek, M.-A. (2017). Control of serpentinisation rate by reaction-induced cracking. Earth and Planetary Science Letters, 476, $143-152$.

Malvoisin, B., \& Brunet, F. (2014). Water diffusion-transport in a synthetic dunite: Consequences for oceanic peridotite serpentinization. Earth and Planetary Science Letters, 403, 263-272.

Malvoisin, B., Brunet, F., Carlut, J., Rouméjon, S., \& Cannat, M. (2012). Serpentinization of oceanic peridotites: 2. Kinetics and processes of San Carlos olivine hydrothermal alteration. Journal of Geophysical Research: Solid Earth, 117(B4).

Martin, W., \& Russell, M. J. (2007). On the origin of biochemistry at an alkaline hydrothermal vent. Philosophical Transactions of the Royal Society B: Biological Sciences, 362(1486), 1887-1926. 
McCollom, T. M., Klein, F., Robbins, M., Moskowitz, B., Berquó, T. S., Jöns, N., Bach, W., \& Templeton, A. (2016). Temperature trends for reaction rates, hydrogen generation, and partitioning of iron during experimental serpentinization of olivine. Geochimica et Cosmochimica Acta, 181, 175-200.

McCollom, T. M., Klein, F., Solheid, P., \& Moskowitz, B. (2020). The effect of pH on rates of reaction and hydrogen generation during serpentinization. Philosophical Transactions of the Royal Society A, 378(2165).

McKinnon, W. B. (2015). Effect of Enceladus's rapid synchronous spin on interpretation of Cassini gravity. Geophysical Research Letters, 42(7), 21372143.

Meyer, J., \& Wisdom, J. (2007). Tidal heating in Enceladus. Icarus, 188(2), 535-539.

Myagkiy, A., Truche, L., Cathelineau, M., \& Golfier, F. (2017). Revealing the conditions of $\mathrm{Ni}$ mineralization in the laterite profiles of New Caledonia: Insights from reactive geochemical transport modelling. Chemical Geology, $466,274-284$.

Neveu, M., Desch, S. J., \& Castillo- Rogez, J. C. (2015). Core cracking and hydrothermal circulation can profoundly affect Ceres' geophysical evolution. Journal of Geophysical Research: Planets, 120(2), 123-154.

Neveu, M., \& Rhoden, A. R. (2019). Evolution of Saturn's mid-sized moons. Nature Astronomy, 1.

Noyelles, B., Baillié, K., Charnoz, S., Lainey, V., \& Tobie, G. (2019). Formation of the Cassini Division-II. Possible histories of Mimas and Enceladus. Monthly Notices of the Royal Astronomical Society, 486(2), 2947-2963. 
Oelkers, E. H. (2001). An experimental study of forsterite dissolution rates as a function of temperature and aqueous $\mathrm{Mg}$ and Si concentrations. Chemical Geology, 175(3-4), 485-494.

Oelkers, E. H., Declercq, J., Saldi, G. D., Gislason, S. R., \& Schott, J. (2018). Olivine dissolution rates: A critical review. Chemical Geology, 500, 1-19.

Okamoto, A., Ogasawara, Y., Ogawa, Y., \& Tsuchiya, N. (2011). Progress of hydration reactions in olivine- $\mathrm{H} 2 \mathrm{O}$ and orthopyroxenite- $\mathrm{H} 2 \mathrm{O}$ systems at $250 \mathrm{C}$ and vapor-saturated pressure. Chemical Geology, 289(3-4), 245-255.

Okland, I., Huang, S., Dahle, H., Thorseth, I., \& Pedersen, R. (2012). Low temperature alteration of serpentinized ultramafic rock and implications for microbial life. Chemical Geology, 318, 75-87.

Olsen, A. A., Hausrath, E. M., \& Rimstidt, J. D. (2015). Forsterite dissolution rates in Mg- sulfate- rich Mars- analog brines and implications of the aqueous history of Mars. Journal of Geophysical Research: Planets, 120(3), 388-400.

O'Neill, C., \& Nimmo, F. (2010). The role of episodic overturn in generating the surface geology and heat flow on Enceladus. Nature Geoscience, 3(2), 88-91.

Park, A.-H. A., \& Fan, L.-S. (2004). CO2 mineral sequestration: Physically activated dissolution of serpentine and $\mathrm{pH}$ swing process. Chemical Engineering Science, 59(22-23), 5241-5247.

Parkhurst, D. L., \& Appelo, C. (2013). Description of input and examples for PHREEQC version 3: A computer program for speciation, batch-reaction, one-dimensional transport, and inverse geochemical calculations (No. 23287055). US Geological Survey. 
Pfeifer, H. (1977). A model for fluids in metamorphosed ultramafic rocks. - I. Observations at surface and subsurface conditions (high $\mathrm{pH}$ spring waters). Schweizerische Mineralogische Und Petrographische Mitteilungen, 57, 361396.

Plümper, O., Røyne, A., Magrasó, A., \& Jamtveit, B. (2012). The interface-scale mechanism of reaction-induced fracturing during serpentinization. Geology, 40(12), $1103-1106$.

Pokrovsky, O. S., \& Schott, J. (2000a). Forsterite surface composition in aqueous solutions: A combined potentiometric, electrokinetic, and spectroscopic approach. Geochimica et Cosmochimica Acta, 64(19), 3299-3312.

Pokrovsky, O. S., \& Schott, J. (2000b). Kinetics and mechanism of forsterite dissolution at $25 \mathrm{C}$ and $\mathrm{pH}$ from 1 to 12. Geochimica et Cosmochimica Acta, 64(19), $3313-3325$.

Pollack, S. S., \& Chi, R. D. (1972). Olivine content of chondrites measured by X-ray diffraction. American Mineralogist: Journal of Earth and Planetary Materials, 57(3-4_Part_1), 584-591.

Porco, C. C., Helfenstein, P., Thomas, P., Ingersoll, A., Wisdom, J., West, R., Neukum, G., Denk, T., Wagner, R., \& Roatsch, T. (2006). Cassini observes the active south pole of Enceladus. Science, 311(5766), 1393-1401.

Postberg, F., Kempf, S., Schmidt, J., Brilliantov, N., Beinsen, A., Abel, B., Buck, U., \& Srama, R. (2009). Sodium salts in E-ring ice grains from an ocean below the surface of Enceladus. Nature, 459(7250), 1098-1101. 
Postberg, F., Schmidt, J., Hillier, J., Kempf, S., \& Srama, R. (2011). A salt-water reservoir as the source of a compositionally stratified plume on Enceladus. Nature, 474(7353), 620-622.

Rimstidt, J. D., Brantley, S. L., \& Olsen, A. A. (2012). Systematic review of forsterite dissolution rate data. Geochimica et Cosmochimica Acta, 99, 159-178.

Robidel, R., Le Mouélic, S., Tobie, G., Massé, M., Seignovert, B., Sotin, C., \& Rodriguez, S. (2020). Photometrically-corrected global infrared mosaics of Enceladus: New implications for its spectral diversity and geological activity. Icarus, 113848.

Rubin, A. E. (1989). Size- frequency distributions of chondrules in CO3 chondrites. Meteoritics, 24(3), 179-189.

Rubin, A. E., Trigo-Rodríguez, J. M., Huber, H., \& Wasson, J. T. (2007). Progressive aqueous alteration of $\mathrm{CM}$ carbonaceous chondrites. Geochimica et Cosmochimica Acta, 71(9), 2361-2382.

Rudge, J. F., Kelemen, P. B., \& Spiegelman, M. (2010). A simple model of reactioninduced cracking applied to serpentinization and carbonation of peridotite. Earth and Planetary Science Letters, 291(1-4), 215-227.

Russell, M. J., Barge, L. M., Bhartia, R., Bocanegra, D., Bracher, P. J., Branscomb, E., Kidd, R., McGlynn, S., Meier, D. H., Nitschke, W., Shibuya, T., Vance, S. D., White, L., \& Kanik, I. (2014). The Drive to Life on Wet and Icy Worlds. Astrobiology, 14(4), 308-343.

Schubert, G., Anderson, J. D., Travis, B. J., \& Palguta, J. (2007). Enceladus: Present internal structure and differentiation by early and long-term radiogenic heating. Icarus, 188(2), 345-355. 
Sekine, Y., Shibuya, T., Postberg, F., Hsu, H.-W., Suzuki, K., Masaki, Y., Kuwatani, T., Mori, M., Hong, P. K., \& Yoshizaki, M. (2015). High-temperature waterrock interactions and hydrothermal environments in the chondrite-like core of Enceladus. Nature Communications, 6 .

1150
Sojo, V., Herschy, B., Whicher, A., Camprubi, E., \& Lane, N. (2016). The origin of life in alkaline hydrothermal vents. Astrobiology, 16(2), 181-197.

Spencer, J., Pearl, J., Segura, M., Flasar, F., Mamoutkine, A., Romani, P., Buratti, B., Hendrix, A., Spilker, L., \& Lopes, R. (2006). Cassini encounters Enceladus: Background and the discovery of a south polar hot spot. Science, 311(5766), 1401-1405.

Thomas, P., Tajeddine, R., Tiscareno, M., Burns, J., Joseph, J., Loredo, T., Helfenstein, P., \& Porco, C. (2016). Enceladus's measured physical libration requires a global subsurface ocean. Icarus, 264, 37-47.

Vance, S. D., Kimura, J., DeMartin, B., \& Brown, J. M. (2007). Hydrothermal systems in small ocean planets. Astrobiology, 7(6), 987-1005.

Vance, S. D., \& Melwani Daswani, M. (2020). Serpentinite and the search for life beyond Earth. Philosophical Transactions of the Royal Society A, 378(2165).

Velbel, M. A., Tonui, E. K., \& Zolensky, M. E. (2012). Replacement of olivine by serpentine in the carbonaceous chondrite Nogoya (CM2). Geochimica et Cosmochimica Acta, 87, 117-135.

Waite, J., Combi, M. R., Ip, W.-H., Cravens, T. E., McNutt, R. L., Kasprzak, W., Yelle, R., Luhmann, J., Niemann, H., \& Gell, D. (2006). Cassini ion and neutral mass spectrometer: Enceladus plume composition and structure. Science, 311(5766), 1419-1422. 

J., Perry, M. E., Miller, K. E., \& Bouquet, A. (2017). Cassini finds molecular hydrogen in the Enceladus plume: Evidence for hydrothermal processes. Science, 356(6334), 155-159.

Waite, J., Lewis, W., Magee, B., Lunine, J., McKinnon, W., Glein, C. R., Mousis, O., Young, D., Brockwell, T., \& Westlake, J. (2009). Liquid water on Enceladus from observations of ammonia and 40Ar in the plume. Nature, 460(7254), 487-490.

Wegner, W. W., \& Ernst, W. (1983). Experimentally determined hydration and dehydration reaction rates in the system $\mathrm{MgO}-\mathrm{SiO} 2-\mathrm{H} 2 \mathrm{O}$. American Journal of Science, 283, 151-180.

White, A. F., \& Brantley, S. L. (2003). The effect of time on the weathering of silicate minerals: Why do weathering rates differ in the laboratory and field? Chemical Geology, 202(3-4), 479-506.

Wogelius, R. A., \& Walther, J. V. (1992). Olivine dissolution kinetics at near-surface conditions. Chemical Geology, 97(1-2), 101-112.

Zhang, K., \& Nimmo, F. (2009). Recent orbital evolution and the internal structures of Enceladus and Dione. Icarus, 204(2), 597-609.

Zhang, L., Nasika, C., Donzé, F., Zheng, X., Renard, F., \& Scholtès, L. (2019). Modeling porosity evolution throughout reaction- induced fracturing in rocks with implications for serpentinization. Journal of Geophysical Research: Solid Earth, 124(6), 5708-5733. 
Zhang, Z., Hayes, A., Janssen, M., Nicholson, P., Cuzzi, J., de Pater, I., Dunn, D., Estrada, P., \& Hedman, M. (2017). Cassini microwave observations provide clues to the origin of Saturn's C ring. Icarus, 281, 297-321. 
Click here to access/download Data in Brief 1D_model_PHREEQC_Zandanel2020.txt 